\title{
Eleições legislativas e geografia do voto em contexto de preponderância do Executivo
}

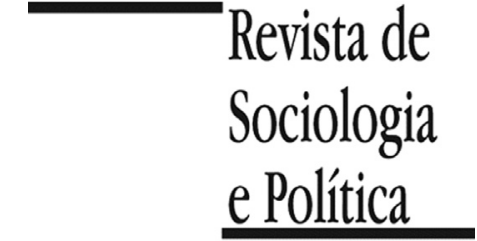

DOI 10.1590/1678-987316245802

\author{
André Borges, Carolina de Paula \\ e Adriano da Nóbrega Silva
}

\section{Resumo}

O artigo analisa o impacto das coalizões governativas nacionais e estaduais sobre a geografia do voto das eleições para a Câmara dos Deputados. O argumento central é que a clivagem governo-oposição tem forte impacto sobre a distribuição territorial de votos de partidos e candidatos. Candidatos cujos partidos participam simultaneamente de coalizões governativas nos níveis nacional e estadual apresentam probabilidade muito maior de dispersar os votos no território dos estados e dominar seus municípios chave. Argumentamos ainda que esse efeito tende a enfraquecer a vantagem do incumbente nas eleições legislativas. Isto é, candidatos incumbentes de oposição apresentam menor capacidade de dominar seus municípios chave em relação a estreantes governistas. A análise empírica se utiliza de uma base de dados com informações dos índices de dominância e concentração de votos de todos os candidatos a deputado federal no período 1998 a 2010. A partir dessa base, estimamos uma série de modelos multivariados para testar os efeitos da participação nos governos estadual e federal e status do candidato (incumbente e estreante) sobre a dominância municipal e grau de concentração/dispersão das votações. Os resultados da análise demonstram que o efeito do posicionamento frente aos governos federal e estadual tem grande peso sobre os padrões de geografia do voto e que o tipo fragmentado-dominante se associa fortemente aos candidatos mais situacionistas. As evidências também indicam que o efeito da incumbência sobre a capacidade dos candidatos de dominar seus municípios-chave é menos relevante do que as vantagens advindas do acesso aos recursos controlados pelo Poder Executivo na esfera federal. O artigo conclui que as hipóteses convencionais sobre a conexão eleitoral merecem ser reavaliadas considerando a preponderância do Poder Executivo e a força dos governos estaduais no presidencialismo brasileiro

PALAVRAS-CHAVE: geografia do voto; eleições legislativas; federalismo; presidencialismo; conexão eleitoral.

Recebido em 25 de Agosto de 2014. Aceito em 1 de Novembro de 2014.

\section{Introdução*}

\footnotetext{
* Agradecemos aos comentários e sugestões realizados pelos pareceristas anônimos da Revista de Sociologia e Política.
}

$\mathrm{N}$ a conhecida formulação da teoria distributivista, o sistema eleitoral majoritário, na presença de condições favoráveis à personalização do voto, cria incentivos para o comportamento paroquial dos membros do Congresso norte-americano com vistas à reeleição, o que foi denominado por Mayhew (2005) como "conexão eleitoral" da atuação dos mesmos. Um dos elementos dessa conexão eleitoral é o fato de que no sistema majoritário os interesses do eleitorado a serem atendidos são geograficamente circunscritos e relacionados às características sociais e econômicas do distrito. Os imperativos da sobrevivência eleitoral levam os parlamentares a basearem sua atividade legislativa na produção de políticas distributivas: para se reeleger eles devem buscar benefícios para os seus distritos.

No caso brasileiro, como se sabe, a combinação entre o sistema eleitoral proporcional de lista aberta e a eleição de parlamentares em distritos de alta magnitude e grande extensão territorial resulta em variadas de estratégias de campanha e tipos de conexão eleitoral. Segundo a tipologia desenvolvida por Ames (2001) existiriam quatro tipos básicos de distrito informal dos deputados 


\footnotetext{
1 A dimensão concentração/fragmentação diz respeito basicamente ao percentual de contribuição dos principais redutos do candidato para a votação total. Por sua vez, a dimensão dominação/compartilhamento pode ser aferida a partir do percentual de votos válidos obtidos pelo candidato em cada município - deputados dominantes são aqueles que obtêm percentuais de votação elevados nos seus municípios-chave.

${ }^{2}$ Veja-se que, em relação ao sistema político, um dos pressupostos básicos do modelo de Mayhew (2005) é que os membros do Poder Legislativo querem ser reeleitos para os cargos que ocupam, o que não necessariamente ocorre no Brasil. Quanto ao sistema eleitoral, como mencionado, o sistema brasileiro é proporcional de lista aberta, ao passo que o norte-americano é majoritário.
}

brasileiros, cada um associado a um padrão distinto de distribuição geográfica do voto: distritos concentrados-dominantes, concentrados-compartilhados, fragmentados-dominantes e fragmentados-compartilhados ${ }^{1}$. Desses quatro, apenas o tipo concentrado-dominante corresponderia, de forma aproximada, ao modelo de conexão eleitoral da teoria distributivista (Carvalho 2003).

Apesar das dificuldades na transposição do modelo distributivista para a análise das eleições legislativas no Brasil, dadas as diferenças entre os sistemas eleitorais e políticos dos dois países ${ }^{2}$, há questões em aberto na literatura que possuem óbvios pontos de contato com esse modelo. Uma delas reside em saber se os mecanismos que governam a construção dos distritos informais são de caráter partidário, individualista ou ambos. Outra consiste em se verificar quais são os efeitos do federalismo robusto (Mainwaring 1997a) e do presidencialismo de coalizão sobre a construção das coalizões eleitorais pelos partidos e por seus candidatos.

Este artigo tem por objetivo avançar no entendimento destas questões, enfatizando os impactos da preponderância do Poder Executivo na arena legislativa sobre a geografia do voto das eleições para a Câmara dos Deputados. A hipótese central é que a definição dos padrões territoriais de votação de deputados e partidos deve acompanhar a clivagem entre governo e oposição nas esferas estadual e federal. Mais especificamente, espera-se que a participação simultânea de um dado partido nas coalizões governativas federal e estadual tenha um efeito cumulativo e positivo sobre a capacidade de os candidatos expandirem a sua base de votação territorial e de dominar municípios-chave. Analogamente, é de se esperar que candidatos de partidos de oposição aos governos federal e estadual, por não contarem com os recursos necessários para dominar seus municípios-chave, prefiram concentrar seus votos em municípios socialmente heterogêneos e de alta competitividade eleitoral. Disso resulta que o tipo de votação fragmentado-dominante tenda a ser mais frequente entre candidatos de partidos de situação no plano federal e estadual.

A dinâmica acima descrita resulta das características institucionais da democracia brasileira. Em um sistema político caracterizado pela preponderância do Poder Executivo, pela existência de um federalismo "robusto" e pela competição partidária centrada no acesso e controle sobre os cargos e verbas governamentais, os presidentes e governadores assumem papel central na construção e reconstrução das coalizões eleitorais.

Por sua vez, o sistema partidário desenvolvido após 1985 se caracteriza pela predominância, à direita e no centro do espectro ideológico, de organizações "mobilizadas internamente", isto é, partidos criados por elites ocupantes de posições governamentais, que lograram mobilizar o eleitorado inicialmente por meio da distribuição de recursos particularistas (Shefter 1994). Apenas os partidos de esquerda, dentre os quais pode-se mencionar o PT (Partido dos Trabalhadores) se adequam à definição de partidos "mobilizados externamente".

A centralidade da clivagem governo-oposição para as estratégias eleitorais dos candidatos à Câmara Federal tem implicações na aplicação, ao caso brasileiro, do postulado da vantagem dos incumbentes (incumbency advantage), presente na teoria distributivista. Conforme o postulado, seria de se esperar que candidatos à reeleição apresentassem, ceteri paribus, maior capacidade dominar eleitoralmente os municípios mais relevantes para a sua votação do que candidatos estreantes em igual condição. Entretanto, argumentamos que as vantagens comparativas intrínsecas ao cargo de deputado são insuficientes para garantir ganhos de dominância no caso brasileiro. Pelo contrário, nossa hipótese é que candidatos incumbentes de oposição encontram-se em desvantagem em 
relação a estreantes que contam com acesso, simultaneamente, a recursos do governo federal e estadual.

A análise empírica se utiliza de uma base de dados com informações obtidas no sítio do Tribunal Superior Eleitoral (TSE), relativas aos padrões territoriais de votação de todos os candidatos a deputado federal no período 1998 a 2010. A partir desta base, estimamos uma série de modelos multivariados para testar os efeitos da participação nos governos estadual e federal e status do candidato (incumbente e estreante) sobre a dominância municipal e grau de concentração/dispersão das votações.

\section{Eleições, partidos políticos, presidencialismo e federalismo no Brasil}

Um passo preliminar à exposição dos padrões territoriais de votação de deputados federais e partidos aqui em análise, bem como o teste da hipótese de que estes deverão acompanhar a clivagem entre governo e oposição nas esferas estadual e federal, é questionar e situar em que medida o conjunto de instituições básicas do sistema político brasileiro - sistema partidário fragmentado, organização territorial federativa e regime presidencialista - oferecem possibilidades e limitações ao estilo de captura de votos dos mesmos.

Sabe-se que o modo de fazer campanha política para o Legislativo no país deriva, em grande medida, de características do nosso sistema eleitoral de lista aberta, em que há centralidade na figura individual do candidato (Carey \& Shugart 1995; Nicolau 2007). Contudo, apenas o enfoque neste aspecto do sistema eleitoral seria insuficiente para compreender nosso objeto de pesquisa, tendo em vista que ao decidir se (re)candidatar um deputado necessita, de acordo com a legislação eleitoral, vincular-se a um partido político.

Outro aspecto a ser considerado é que a coincidência do calendário eleitoral no Brasil entre as eleições para o Legislativo e para o Executivo nacional e subnacional coloca em questão o papel da conexão de ambos os pleitos. $\mathrm{Na}$ literatura, a proximidade de data entre os pleitos resulta em um efeito conhecido como coat tail, segundo o qual os eleitores que votam no candidato presidencial que sai vencedor no pleito normalmente votam nos candidatos ao Congresso que pertencem à mesma sigla partidária (Golder 2006; Shugart \& Carey 1992; Soares 2013). Em paralelo, o fortalecimento dos poderes do Executivo após 1988, que incluiu a manutenção de poderes "legiferantes" do período autoritário (Santos 2003), em detrimento de competências exclusivas do Legislativo, impulsiona o analista a considerar o papel do ocupante da cadeira de governador/presidente nesse jogo.

É preciso mencionar, ainda, que os partidos políticos operam em contextos estaduais diversos nos quais o volume de acesso aos recursos orçamentários depende, e muito, da relação com o partido/coalizão do governador/presidente. Sabendo que eleições não se fazem sob tabula rasa, estratégias eleitorais partidárias dependerão do passado recente da atuação e posição do partido em nível estadual e federal.

Por fim, a trajetória política e pessoal do próprio candidato à Câmara dos Deputados deve ser levada em conta na análise, pois a carreira e a biografia do candidato podem influenciar seu modo de inserção na arena eleitoral. Por exemplo, o candidato que é incumbente encontra-se em posição mais vantajosa que outro que seja desafiante? Conhecida na literatura como "incumbency advantage", a questão está longe do consenso. De um lado estão os adeptos da "tese do trampolim", que veem diminuto impacto dos benefícios do mandato parlamentar para os quais a atuação dos legisladores brasileiros estaria, em muitos casos, voltada à busca pela viabilização de suas candidaturas para outros cargos (Samuels 2003). De outro lado, encontram-se os que apostam na ambi- 
ção estática e na importância desses atributos intrínsecos ao mandato parlamentar para a reeleição (Leoni, Pereira \& Rennó 2003; Paranhos et al., 2014). Ambos os posicionamentos acerca do caso brasileiro não analisaram, contudo, se as vantagens advindas do posicionamento parlamentar frente ao governo refletiriam posteriormente num benefício eleitoral.

II.1. Partidos deputados e geografia do voto

Adotar a perspectiva da geografia do voto neste debate no qual estamos inseridos começa a ganhar cada vez mais fôlego na Ciência Política (Terron 2012). Em alguma medida tal viés interage com os estudos pioneiros da sociologia eleitoral no país - por exemplo, Fleischer (1976); Soares (2001); Indjaian (1981); Dias (1991) - porém, os trabalhos recentes ultrapassam a dicotomia do voto urbano-rural para compreender a complexa estrutura social, política e econômica na qual os candidatos ao Legislativo buscam angariar votos. No que tange especificamente à distribuição espacial de votos ao Legislativo, a pesquisa de Ames (2001) e Carvalho (2003) podem ser consideradas ilustrações de duas correntes interpretativas pelo qual deputados e partidos têm seus votos distribuídos pelo território. Ames (2001) desenvolve uma tipologia de "distritos" informais: (i) concentrados-dominantes; (ii) concentrados-compartilhados; (iii) dispersos-dominantes; (iv) dispersos-compartilhados.

Deputados de votação concentrada e dominante são usualmente parlamentares de reduto, de orientação paroquial. Este tipo de deputado geralmente domina uma região de municípios geograficamente contíguos, a partir de um município-chave onde obtém alta votação. A dominância costuma vir associada a uma trajetória prévia na política local, como é o caso de parlamentares ligados a uma família política com tradição no município, ex-prefeitos e ex-vereadores etc. (Ames 2001; Carvalho 2003).

Os deputados do tipo fragmentado-dominante apresentam votação dispersa por vários municípios e alto grau de dominância média, o que reflete a sua capacidade de estabelecer redes de apoio e clientela difusas e dissociadas de uma atuação política prévia em regiões específicas do estado. Estes são tipicamente parlamentares com passagem por postos burocráticos estaduais com potencial de implementação de políticas distributivas (e.g., secretários estaduais de infraestrutura, educação, saúde, etc.) (Carvalho 2003).

Já os deputados com votação concentrada-compartilhada são encontrados principalmente nas capitais e nos grandes centros urbanos. Por conta da grande dimensão dos colégios eleitorais onde obtêm votos, os deputados estão longe de poder dominar esses municípios. Via de regra, são representantes que se reportam a setores de opinião difusos nesses grandes municípios e estariam mais voltados à tomada de posição em relação a temas do que a perseguição de benefícios particularizados (idem).

Por fim o tipo fragmentado-compartilhado apresenta votação percentual baixa e geograficamente difusa. Estes são parlamentares que conseguem projeção em todo o estado, apresentando, porém, menor dependência de redes locais. A sua base de votação pode ser resultado do prestígio político adquirido com a ocupação de cargos de expressão estadual ou nacional (tanto eletivos quanto administrativos). Em outros casos, estes deputados podem mobilizar um voto mais ideológico, de caráter religioso ou issue-oriented, mobilizando minorias difusas em todo o estado (a exemplo de parlamentares ambientalistas ou evangélicos). 


\section{II.1.1. A clivagem governo-oposição e seu impacto sobre os padrões de votação}

${ }^{3}$ Outros estudos analisaram a conexão eleitoral na esfera subnacional, observando a existência de associações entre a produção legislativa e a geografia dos votos (Borges 2005; Veiga et al., 2008)
Percebe-se, no entanto, uma ausência nos trabalhos mencionados ${ }^{3}$. Ames (2001) e Carvalho (2003) não consideram em suas pesquisas o posicionamento do candidato - nem de seu partido- dentro da dinâmica da coalizão de governo, seja em nível estadual, seja federal. Tal ausência reflete de alguma maneira a perspectiva sob a qual o debate relativo ao distributivismo se desenvolveu na literatura brasileira. Na tentativa de enquadrar o modelo brasileiro de comportamento parlamentar às premissas distributivistas para o Congresso norteamericano, os trabalhos no Brasil utilizaram variáveis analíticas análogas às descritas por Mayhew (2005).

Apesar de reconhecer que não é possível transpor as hipóteses distributivistas sem adaptações ao caso brasileiro, Ames (2001) defende a tese de que o sistema eleitoral proporcional de lista aberta induz os deputados a prover benefícios para as suas clientelas eleitorais. Contudo, há significativas diferenças entre os padrões de relação do presidencialismo de coalizão no Brasil e no presidencialismo nos EUA que impactam as estratégias de sobrevivência política dos parlamentares. No Brasil observa-se a operação de um presidencialismo "parlamentarizado", no qual coalizões majoritárias formadas pelo presidente controlam a agenda legislativa. O Poder Executivo é preponderante, enquanto o Congresso tem papel muito mais reativo do que propositivo (Cox \& Morgenstern 2001; Colomer \& Negretto 2005; Amorim Neto 2007). Nos EUA, ao contrário, há uma maior independência entre o Executivo e o Legislativo, e as comissões legislativas são de direito e de fato, o lócus de produção de políticas públicas. Assim, nesse país, a experiência legislativa e a participação em postos de importância no Congresso têm peso muito mais significativo na construção das carreiras (Fiorina 1977; Wood \& Waterman 1991; Mayhew 2005; Jacobson 2009). Considerando estes aspectos, fica claro ser necessário agregar outros elementos a fim de compreender o impacto da atividade legislativa sobre a geografia do voto no caso brasileiro. Um desses elementos é exatamente o posicionamento do deputado na coalizão de governo, tanto nacional quanto estadual.

Pesquisas recentes parecem caminhar nessa direção. Inácio (2011), em "Engajamento Parlamentar no Brasil", utiliza dois surveys com parlamentares um survey nacional envolvendo 139 deputados federais e senadores e outro em âmbito subnacional, envolvendo 513 deputados em 12 Assembléias Legislativas - para avaliar a percepção dos parlamentares acerca de três diferentes tipos de engajamento no Legislativo: atividades voltadas para produção de benefícios particularizados para a base local/regional - pork barrel; atividades focadas na intermediação de demandas dos eleitores e políticos regionais junto às burocracias públicas - casework; e atividades relacionadas à elaboração de leis - policy making (idem, p.174). Os resultados de Inácio (idem) apontam que o empenho em atividades de pork barrel seria mais significativo de acordo com o pertencimento, ou não, à base governista, sendo a legenda do parlamentar e o seu posicionamento no espectro ideológico irrelevantes em termos de significância estatística. No que diz respeito às atividades de intermediação de demandas (casework), os deputados governistas apresentam maior propensão a perseguir este tipo de estratégia - o que reflete uma maior facilidade de acesso dos partidos aliados às burocracias federais.

Neste trabalho, seguindo as pistas apontadas pelo trabalho de Inácio (idem), procuramos demonstrar que as diferenças relativas à geografia do voto dos partidos na Câmara dos Deputados não refletem tão somente fatores como características dos candidatos (ex. estreantes vs. postulantes à reeleição), organização interna e coerência ideológica das organizações partidárias, mas também, e principalmente, o posicionamento dos partidos com respeito aos 
governos estadual e federal (situação ou oposição) e, em decorrência disso, a capacidade dos partidos de obter acesso a cargos e recursos controlados pelo Poder Executivo.

O cerne do nosso argumento é que o acesso a cargos e recursos públicos nos planos federal e estadual impacta as estratégias eleitorais dos candidatos a deputado federal e, em consequência, os seus padrões de votação. Em termos mais precisos, a interseção, em cada distrito, entre os posicionamentos dos partidos frente às coalizões governativas federal e estadual tem efeito cumulativo sobre a capacidade de os candidatos expandirem a sua base de votação territorial e/ou de dominar municípios chave.

Boa partes dos esforços empreendidos pela literatura sobre conexão eleitoral no Brasil foram dedicados ao entendimento dos impactos das emendas parlamentares ao orçamento da União, ou da atuação na Comissão Mista de Planos, Orçamentos Públicos e Fiscalização (CMO) sobre a probabilidade de sucesso dos candidatos à reeleição (Mesquita 2008; Pereira \& Rennó 2001; 2007). Mais recentemente, pode ser mencionado estudo que relaciona as chances de reeleição à atuação dos deputados federais na Comissão Mista de Orçamento (Lemgruber 2010).

Essas análises acerca da atuação dos parlamentares no processo legislativo orçamentário deixam de lado a possibilidade de candidatos à Câmara Federal, incumbentes ou desafiantes, beneficiarem-se diretamente da sua proximidade com o Executivo. Parlamentares cujos partidos participam do gabinete presidencial podem, por exemplo, beneficiar-se de atividades de casework, intermediando a celebração de convênios entre o ministério e prefeituras dos seus redutos eleitorais, ou atuando junto à burocracia dos bancos federais para agilizar a concessão de empréstimos aos financiadores da campanha. Este tipo de atividade não passa pelo Legislativo, mas certamente constitui parte relevante das atividades parlamentares, a considerar os resultados da já citada pesquisa de Inácio (2011).

Há que se considerar também a importância da ocupação de cargos do alto escalão estadual para as carreiras dos parlamentares brasileiros. Em uma análise dos padrões de carreira dos deputados federais da 52a legislatura, Bourdoukan (2006) demonstrou que a busca por cargos eletivos e não-eletivos no Executivo, especialmente na esfera subnacional, constitui importante porta de entrada na vida política. Cerca de 15,8\% dos 513 deputados eleitos em 2002 começaram a carreira em cargos de secretários municipais ou estaduais ou ministros (sendo $7 \%$ de secretários estaduais e $8 \%$ de secretários municipais) (idem, p.12). Santana (2008) encontrou padrão semelhante para todas as legislaturas do período 1990-2002: em média, 25,8\% dos parlamentares eleitos nessas legislaturas haviam ocupado anteriormente o cargo de deputado estadual e $18 \%$ haviam sido nomeados para cargos do $1^{\circ}$ escalão da administração estadual. Os percentuais médios para cargos locais (prefeito e vereador) foram de $12,5 \% \mathrm{e}$ $16,6 \%$ respectivamente.

A relevância da arena estadual - não obstante estudos recentes que apontam para uma recentralização do federalismo brasileiro (Almeida 2005; Arretche 2007; Fenwick 2009; Borges 2013) - decorre ainda de fatores institucionais já conhecidos: a legislação eleitoral estabelece os estados como distritos, e as decisões sobre as listas de candidatos ao Senado e a Câmara Federal são tomadas no plano estadual. Os governadores e outras lideranças partidárias estaduais são atores influentes no estágio de definição de candidaturas ao legislativo federal (Samuels 2003). A competição para a Câmara é moldada em grande parte por questões locais e não nacionais, uma vez que a capacidade de os candidatos trazerem benefícios para os seus redutos têm grande peso na mobilização dos eleitores (Ames, Baker \& Rennó 2008). Ames (2001) chamou 
a atenção para o fato de que em alguns estados governadores controlam o lançamento de candidaturas e dominam as campanhas eleitorais.

Note-se que um partido pode fazer oposição ao governador num determinado estado, e ao mesmo tempo ser integrante do gabinete presidencial. Assim, os candidatos a deputado federal deste partido podem compensar a incapacidade de obter acesso a recursos controlados pelo Executivo estadual por conta da sua participação no Executivo nacional. Imaginemos, para simplificar, que o ministro de uma pasta com grande capacidade de realização de obras públicas seja vinculado à seção estadual deste partido. Vamos supor ainda que o ministro e o governador lideram grupos políticos adversários, e que ambos desejam ampliar a sua influência sobre a bancada do estado na Câmara. Neste caso, o ministro poderia direcionar as obras do seu ministério para determinados municípios do estado, com o objetivo de fortalecer as bases eleitorais de deputados federais do seu partido, ou de deputados estaduais, ou prefeitos que almejam obter uma vaga na Câmara. Por sua vez, o governador agiria na direção contrária, tentando fortalecer os candidatos do seu grupo político e enfraquecer os do grupo adversário.

Em outra situação hipotética, poderíamos ter o ministro e o governador vinculados ao mesmo partido e imbuídos do mesmo objetivo de aumentar a bancada em Brasília, de modo que os candidatos a deputado federal da sigla se beneficiariam duplamente: por um lado, dos recursos controlados pelo Executivo estadual, e do outro, dos recursos federais. Neste caso há um duplo ganho: um ganho do ponto de vista de recursos e um ganho do ponto de vista da coordenação intergovernamental.

Num regime federativo como o brasileiro, a implementação de diversas políticas públicas requer a coordenação entre instâncias decisórias de níveis distintos de governo, o que tem implicações para a capacidade que os atores políticos têm de reivindicar para si o crédito (credit-claiming) pelos resultados alcançados. Determinados programas podem, por exemplo, ser financiados majoritariamente pela União, ou conjuntamente pela União e Estados, sendo, no entanto, implementados pelo ente subnacional. Quando um mesmo partido/coalizão controla as instâncias decisórias relevantes no plano federal e estadual, e há alto grau de discricionariedade nas decisões, os incentivos à coordenação são maiores, uma vez que, independente de quem implementa e financia a ação governamental, os membros do partido/coalizão serão os principais beneficiários, recebendo o crédito pela ação.

Cenário distinto é aquele em que um partido se encontra na oposição em ambos os níveis de governo. Sem o apoio da máquina dos governos federal e estadual, os candidatos deste partido de oposição "pura" teriam de contar com outros recursos (por exemplo, recursos organizacionais e financeiros do partido, acesso a cargos e verbas de prefeitura), além de enfrentar sério risco de ver os candidatos apoiados pelo governador e pelo ministro "invadirem" os seus redutos.

É preciso ressaltar que a filiação a um partido governista no plano estadual ou federal, por si só, não é condição suficiente para que aspirantes a deputado desfrutem de condições privilegiadas na disputa por uma cadeira na Câmara, uma vez que no interior de um mesmo partido pode haver grande variação no grau de experiência política e possibilidade de acesso a recursos controlado pelo Executivo ${ }^{4}$. Certamente, candidatos que já ocupam cargos públicos, como deputado estadual ou federal ou secretário de estado, têm maior probabilidade de se beneficiar do apoio dos governos federal, estadual ou ambos. Feita esta ressalva, parece razoável supor que, ceteris paribus, candidatos governistas desfrutam, na média, de condições mais favoráveis para construir redutos

eleitorais menos vulneráveis, relativamente aos candidatos de oposição.

4 Agradecemos a um dos pareceristas anônimos da Revista de Sociologia e Política por nos chamar a atenção para este ponto. 
Considerando o caráter multipartidário do presidencialismo brasileiro é de se esperar que haja diferenças significativas no posicionamento dos partidos frente aos governos nacional e estadual. Por exemplo, não é incomum partidos que são aliados no nível nacional serem adversários na esfera estadual. Assumindo uma dicotomia simples entre situação-oposição no nível federal e estadual, é possível obter a tabela 2x2 apresentada no Quadro 1.

Em uma situação em que os principais partidos competidores na arena estadual se localizam nos quadrantes I e IV, deve-se esperar uma significativa diferenciação dos padrões territoriais de voto. Na média, os candidatos do partido que monopoliza o acesso a verbas e cargos federais e estaduais (I) têm maior probabilidade de serem bem-sucedidos na criação de barreiras à entrada de competidores eleitorais nos seus redutos, desenvolvendo padrões de votação dominante. Esse tipo de estratégia tende a prosperar em municípios pequenos, com economias frágeis e dependentes de recursos públicos. Em tal contexto, os intermediários locais contam com mais instrumentos para influenciar o voto, controlando a acesso a bens e serviços desejados pelos eleitores (Diaz-Cayeros, Magaloni \& Weingast 2003; Stokes 2005). Candidatos capazes de trazer recursos federais ou estaduais para o município têm evidente vantagem: estes recursos podem ser utilizados de forma indireta, para comprar o apoio das lideranças locais (por exemplo, com a construção de uma estrada que beneficia os proprietários de terra da região) ou diretamente, para mobilizar o apoio de grupos de eleitores (Ames 2001, p.80). A dominância eleitoral pode resultar não apenas dos esforços do candidato para erigir barreiras à entrada através da alocação estratégica de recursos, mas também da coordenação intrapartidária: dado que o sistema proporcional recompensa votações agregadas mais elevadas com cadeiras adicionais, os líderes partidários podem agir no sentido de evitar a competição entre colegas de sigla nos mesmos redutos eleitorais (Silva et al., 2010).

Por suposto, candidatos localizados no quadrante IV da tipologia estão excluídos do acesso a recursos controlados pelo Executivo estadual e federal. Deste modo, a entrada em mercados eleitorais onde a competição se baseia fundamentalmente na distribuição de benefícios materiais e divisíveis torna-se extremamente custosa e arriscada. Portanto, este tipo de candidato apresenta maior probabilidade de concentrar esforços em mercados de voto compartilhado, onde a heterogeneidade social do eleitorado é maior e há menos dependência de partidos e eleitores frente aos recursos públicos. As estratégias de campanha de candidatos oposicionistas e governistas tendem a diferir significativamente porque, na ausência de recursos para distribuir entre membros e apoiadores, partidos de oposição precisam construir vínculos de natureza ideológica e programática para sobreviver eleitoralmente (Shefter 1994).

No que diz respeito à dispersão espacial da votação, candidatos governistas situados no quadrante I tendem a apresentar, na média, distribuições mais fragmentadas relativamente aos candidatos oposicionistas "puros" (quadrante IV). A principal razão para isso é que, via de regra, o custo de fazer campanha

Quadro 1 - Matriz de posicionamento dos partidos frente aos governos estadual e federal

\begin{tabular}{lcc}
\hline Governo Federal & \multicolumn{2}{c}{ Governo estadual } \\
\cline { 2 - 3 } & Situação & Oposição \\
\hline Situação & I & III \\
Oposição & II & IV \\
\hline
\end{tabular}

Fonte: Os autores. 
em muitos municípios, especialmente em estados de grande extensão territorial, é mais elevado do que concentrar esforços em poucos municípios geograficamente contíguos. Candidatos oposicionistas enfrentam cenário de escassez de recursos relativamente aos seus competidores que contam com o apoio da máquina governamental, de modo que a estratégia mais racional, em muitos casos, é concentrar recursos em poucos municípios onde se espera obter melhores retornos eleitorais. Candidatos governistas não enfrentam esta restrição: mesmo aqueles que iniciam sua carreira com bases eleitorais concentradas (a exemplo de ex-prefeitos) podem se valer da capacidade de influenciar a alocação de verbas para obras do governo estadual ou federal com o intuito de expandir a sua base inicial de votação, conquistando eleitores de municípios contíguos.

A partir das colocações acima, podemos estabelecer três hipóteses:

I. Candidatos de partidos situacionistas no plano federal e estadual apresentam maior propensão a desenvolver padrões de votação caracterizados por índices de dominância e fragmentação elevados, relativamente aos candidatos de oposição nos planos estadual ou federal, ou ambos. Isto é, o tipo de votação fragmentado-dominante tende a ser mais frequente no quadrante I da tipologia.

II. Candidatos que não contam com acesso aos recursos controlados pelos executivos estadual e federal tendem a desenvolver padrões de votação de perfil exatamente oposto, com baixos índices de dominância e fragmentação, compartilhando votos com outros candidatos, votos esses, contudo, concentrados geograficamente.

III. Dada a importância da arena estadual para a disputa ao legislativo federal, a participação no governo estadual de partidos oposicionistas no plano federal (quadrante II) deve gerar ganhos de dominância e fragmentação tão ou mais expressivos do que aqueles obtidos por candidatos de partidos situacionistas no plano federal, mas que fazem oposição ao governador (quadrante III).

Uma das implicações das hipóteses acima é que as diferenças entre os padrões de votação dos deputados federais do PT e aqueles observados para os deputados dos partidos de centro e direita, conforme o estudo de Carvalho (2003), resultam em parte do fato de que esta organização esteve na oposição ao governo federal (e também, em muitos casos, aos partidos da situação nos estados) durante todo o período estudado pelo autor. Ou seja, acreditamos que a preponderância do padrão de votação concentrado-compartilhado no PT, em contraste à prevalência do tipo fragmentado-dominante no PMDB e PFL se deve aos posicionamentos opostos destes partidos no eixo situação oposição. Enquanto PMDB e PFL se constituíram como partidos de orientação governista após a transição à democracia, o PT e todos os partidos de esquerda, com poucas exceções, atuaram na oposição ao governo federal ao longo de boa parte do recente período democrático.

Isso não quer dizer, entretanto, que não haja um efeito independente das organizações partidárias sobre os padrões de votação. Marenco e Serna (2007) argumentam que os parlamentares de esquerda são normalmente recrutados no setor público, classe média assalariada, profissões intelectuais, sindicalistas e lideranças de movimentos sociais, sendo mais dependentes da estrutura organizacional partidária e associativa para obter o sucesso eleitoral. Em razão desse padrão de recrutamento, candidatos de partidos de esquerda apresentam maior propensão a realizar campanhas calcadas na ideologia e na reputação partidária. Estratégias eleitorais desta natureza, por sua vez, tendem a estar associadas a votações compartilhadas e concentradas; ou de tipo fragmentado-compartilhado (Carvalho 2003). Disso, extraímos a quarta hipótese: 
IV. Candidatos de esquerda apresentam mais propensão a desenvolver votações compartilhadas e menor probabilidade de combinar alta fragmentação e alta dominância, relativamente aos candidatos de centro e de direita.

Para o modelo distributivista, a experiência em Washington e a antiguidade na arena legislativa impactam positivamente a capacidade de os parlamentares lidarem com a burocracia e produzir políticas públicas sob medida para os seus distritos, de modo que a vantagem competitiva dos postulantes à reeleição sobre os desafiantes se ampliaria ao longo do tempo (Fiorina 1977; Mayhew 2005; Jacobson 2009). No que diz respeito a este postulado, argumentamos que a vantagem competitiva dos incumbentes é decorrência do acesso dos parlamentares aos recursos controlados pelo Executivo federal ou estadual, como cargos e verbas. A questão é saber se, e em que medida, os candidatos à reeleição apresentam maior probabilidade de dominar seus municípios-chave, tudo o mais mantido constante. Dadas as nossas hipóteses anteriores, podemos deduzir que deputados que contam com acesso privilegiado aos recursos controlados pelo Executivo federal ou estadual ou ambos têm mais oportunidades para construir e manter redutos dominantes por meio de atividades pork barrel e casework.

Outra questão relacionada é saber se os ganhos de dominância esperados para os candidatos incumbentes independem do tipo de reduto eleitoral, se fragmentado ou concentrado. Conforme Ames (2001), candidatos de votação concentrada são vulneráveis à incursão de candidatos adversários nas suas bases, em razão da elevada competitividade do sistema proporcional de lista aberta. Disso resulta que a estratégia mais frequente entre os deputados concentrados é conquistar municípios vizinhos ao seu centro de votação, expandindo territorialmente as suas bases. Por outro lado, pode-se inferir que deputados concentrados incapazes de dispersar territorialmente as suas bases tendem a ser mais fracos eleitoralmente.

Podemos assim estabelecer a quinta e a sexta hipóteses abaixo:

V. Candidatos incumbentes de oposição aos governos federal e estadual apresentam na média, menor capacidade de dominar seus municípios-chave, relativamente a candidatos estreantes de situação, especialmente aqueles que contam com acesso a recursos federais e estaduais simultaneamente.

VI. Candidatos incumbentes de votação concentrada têm menor capacidade de dominar seus municípios chave relativamente àqueles de votação fragmentada. No caso específico de candidatos incumbentes concentrados e de oposição, esperamos encontrar uma desvantagem competitiva em relação a candidatos semelhantes de situação.

\section{Padrões territoriais de votação dos candidatos a deputado federal}

Para testar as hipóteses levantamos dados relativos aos padrões de votação de todos os candidatos a deputado federal no período de 1998 a 2010. Os dados foram obtidos junto ao TSE. Como fonte complementar, utilizamos a base de dados de resultados eleitorais por município do Centro de Estudos da Metrópole da Universidade de São Paulo (CEM-USP), que facilitou enormemente o trabalho de cálculo dos votos válidos para deputado federal no período de análise. A partir das planilhas originais, utilizamos uma série de rotinas do software R statistics para calcular dois índices de concentração-dispersão de votos (índice de Rae invertido e índice g), além do índice de dominância municipal.

As dimensões de dominância e fragmentação originalmente desenvolvidas por Ames (2001) foram operacionalizadas e aplicadas à análise da votação no 
${ }^{5}$ A fórmula é dada por $1 /(\Sigma$ $\left.\mathrm{Ci}^{2}\right)(\mathrm{i}=1 \ldots \mathrm{N})$, sendo 'Ci' a contribuição do município e ' $\mathrm{i}$ ' a votação total do candidato no estado. nível municipal dos candidatos a deputado federal. O índice de dominância pode ser calculado pela fórmula

$$
\sum_{i} \frac{\left(V_{i} C_{i}\right)}{100}
$$

sendo $V i$ a votação no município (\% de votos válidos), $C i$ a contribuição do município i à votação total do partido, e $\mathrm{N}$ o total de municípios no distrito eleitoral (estado). Um alto índice de dominância indica que os municípios mais importantes para o candidato (do ponto de vista da contribuição à votação total) se caracterizam por votações médias elevadas.

O grau de concentração das votações dos candidatos foi operacionalizado com a utilização do índice de Rae invertido, muito usado como medida de fragmentação das cadeiras entre os partidos com representação no Congresso. A fórmula pode ser utilizada também como medida de dispersão/concentração dos votos do candidato entre os municípios do estado 5 . Este indicador nos dá uma ideia aproximada do número de municípios de votação efetiva do candidato (Carvalho 2003). Denominamos esta medida de número efetivo de municípios (NEM) ao longo da análise empírica.

Utilizamos ainda uma segunda medida de concentração-dispersão de votos - o índice g - que considera o peso de cada município com respeito ao total de votos válidos no estado (Avelino, Biderman \& Silva 2011). O índice g é calculado pela fórmula a seguir:

$$
\sum_{i}\left(C_{i}-M_{i}\right)^{2}
$$

sendo $C_{i}$ a contribuição do município i à votação total do candidato e $M_{i}$ a participação total de votos válidos no município i no total de votos do estado. Quando o valor de g é nulo isso significa que a distribuição de votos do candidato é exatamente igual a distribuição de votos válidos no estado. Matematicamente, isso significa dizer que o percentual de votos obtidos com respeito ao total de cada município é exatamente igual em todos os municípios, e idêntico ao percentual de votos obtidos no estado inteiro. Essa seria a situação de dispersão máxima de votos, uma vez que, para obter esse resultado, o candidato deveria, hipoteticamente, alocar de forma absolutamente equânime entre os municípios os recursos disponíveis para a campanha eleitoral. De forma análoga, valores elevados de $\mathrm{g}$ indicam desproporção entre a distribuição de votos válidos no estado e a distribuição de votos do candidato e, portanto, votações concentradas.

A principal força do índice g é também a sua fraqueza porque, ao considerar a distribuição dos votos em cada estado, a comparabilidade do índice torna-se prejudicada. Isto porque obter um índice g de zero em no estado do Acre, que conta com apenas 22 municípios, tem significado totalmente distinto de obter o mesmo índice em um estado com mais de 600 (caso de São Paulo). Obviamente, por razões de extensão territorial e custos relacionados de campanha, é muito mais difícil fazer campanha e obter a mesma votação em todos os municípios em São Paulo do que no Acre.

O índice g também é de difícil interpretação enquanto medida de concentração dos votos. Dada a forma de cálculo do indicador, não há como saber o que significa um índice g de 0,50 , ou quão mais concentrado é um candidato com $g=0,50$ relativamente a um outro com $g=0,30$. Neste aspecto, o número efetivo de municípios é de interpretação mais intuitiva, porque um NEM = 1 significa que o candidato concentrou $100 \%$ dos seus votos em um único município. Quanto mais próximo o índice do valor unitário, tanto maior a probabilidade de se tratar de um candidato de tipo concentrado, cuja base de votação é territorialmente restrita. Também podemos argumentar persuasi- 
vamente que um candidato com NEM = 3 possui uma distribuição cerca de duas vezes mais dispersa que outro com $\mathrm{NEM}=1,5$. Por fim, apesar do limite superior do NEM estar correlacionado com o número de municípios no distrito, este problema foi contornado nos modelos de regressão com a inclusão de uma variável de controle que mede o total de municípios por estado.

Considerando que o número efetivo de municípios é de mais fácil interpretação, preferimos utilizar esse indicador em lugar do índice g nas análises multivariadas. Na exposição descritiva dos dados, apresentamos ambos os indicadores.

Para a classificação dos partidos no eixo-situação oposição, nos baseamos primeiro em informações relativas às coalizões governativas e eleitorais nacionais. Inicialmente, estabeleceu-se como critério para classificar os partidos no eixo situação a ocupação de cargos de alto escalão por mais de $50 \%$ do período do mandato do presidente. Adicionalmente, como exceção a este critério, considerou-se como "situação" o partido que, apesar de não ter participado da coalizão governativa durante todo ou mais de $50 \%$ do mandato, obteve cargos de alto escalão nos biênio pré-eleitoral, firmando aliança com o partido governista na eleição seguinte. Neste caso, adotou-se o pressuposto de que estes partidos se beneficiariam da aceleração dos gastos públicos no período préeleitoral e da aliança firmada com o partido governista, em que pese o curto tempo de participação efetiva na coalizão de governo.

Com esta definição dos partidos governistas no plano nacional, excluímos partidos que não ocuparam pastas ministeriais, mas, no entanto, apoiaram o presidente no Congresso. Esta exclusão se justifica porque o nosso argumento diz respeito fundamentalmente ao controle dos partidos sobre a burocracia federal, não incluindo outros benefícios obtidos pelas organizações partidárias em troca do apoio ao governo.

Infelizmente, dada a ausência de informações disponíveis para as coalizões governativas em todos os estados no período em análise, utilizamos como proxy a filiação do candidato ao partido do governador em exercício no ano eleitoral. Com isso obtivemos categorias um pouco distintas daquelas definidas na tipologia:

a) governador da coalizão: candidatos cujos partidos controlam um ou mais ministérios e o governo do estado;

b) coalizão: candidatos de partidos de situação no nível federal que não controlam o governo do estado;

c) governador: candidatos de partidos não presentes no gabinete presidencial, mas que controlam a governadoria;

d) categoria base: reúne todos os partidos que não controlam nem ministérios e nem a governadoria.

Esta limitação nos dados não nos permite separar claramente partidos que não participam de coalizões nacionais e estaduais daqueles que participam da coalizão em uma ou nas duas esferas de governo, uma vez que alguns partidos na categoria-base podem participar do secretariado estadual apesar de não contarem com ministérios. Entretanto, há que se considerar que possíveis vieses decorrentes desta limitação são desfavoráveis ao teste das nossas hipóteses: isto é, se as diferenças que esperamos encontrar entre candidatos governistas e oposicionistas no plano estadual forem pequenas é maior a probabilidade aceitarmos a hipótese de nula de ausência de diferença. Uma vez que estaremos comparando candidatos filiados ao partido do governador com outros não filiados, mas que também contam com acesso aos recursos do Executivo. 
${ }^{6}$ Como o Distrito Federal possui um único município, não seria possível calcular adequadamente os índices de concentração de votos. Uma alternativa seria obter os índices para as zonas eleitorais; o problema desse procedimento é o risco de incorrer em distorções na mensuração devido à aplicação de unidades de análise distintas (município e zonas eleitorais) para o DF e demais estados.
Apresentamos a seguir as médias do índice g, número efetivo de municípios e dominância para o total de candidatos que concorreram nas eleições para a Câmara Federal de 1998 a 2010, à exceção daqueles que disputaram a eleição no $\mathrm{DF}^{6}$. Acrescentamos na mesma tabela um indicador simples de concentração que mede a contribuição dos cinco municípios de maior votação absoluta para a votação total do candidato (Tabela 1 ).

A tabela mostra razoável estabilidade nos valores médios de dispersãoconcentração de votos entre 1998 e 2010. A dominância média experimentou queda no período, o que pode ser decorrência do crescimento no número de candidatos e maior competitividade nos distritos. É interessante notar que a concentração de votos em poucos municípios é característica comum à maioria dos candidatos: considerando todas as eleições, $60 \%$ os candidatos a deputado federal concentraram percentual igual ou superior a $74 \%$ dos votos nos cinco municípios de maior votação absoluta.

A Tabela 2 mostra as médias para os mesmos indicadores incluindo apenas os candidatos eleitos. O total de eleitos soma 505 a cada ano por conta da exclusão do Distrito Federal da base.

Quando consideramos apenas os eleitos, obtemos taxas de dispersão dos votos bem mais elevadas. O mesmo vale para a dominância municipal: a média para os eleitos chegou a ser três vezes maior do que a média geral nos anos de 2002, 2006 e 2010. Estes resultados não são surpreendentes se considerarmos que a dominância se encontra correlacionada, em alguma medida, com a votação total dos candidatos. Por outro lado, candidatos que obtém votações muito baixas tendem a ser, via de regra, altamente concentrados. Se considerarmos somente os candidatos com votação inferior a $0,2 \%$ dos votos válidos no distrito, temos uma distribuição com $75 \%$ dos casos concentrando $70 \%$ ou mais dos seus votos nos cinco municípios de maior votação absoluta.

Uma vez que a inclusão dos candidatos de votação desprezível poderia distorcer as análises no que diz respeito a inferências sobre as estratégias eleitorais adotadas, decidimos estabelecer um valor mínimo de votação para a

Tabela 1 - Médias anuais para a dominância, número efetivo de municípios e contribuição dos 5 municípios de maior votação absoluta - Candidatos a deputado federal, 1998-2010

\begin{tabular}{lccccc}
\hline Ano & N & Dominância & NEM & g & Cont. 5+ \\
\hline 1998 & 3275 & 6.26 & 5.45 & 0.269 & 74.89 \\
2002 & 4087 & 4.75 & 5.80 & 0.276 & 74.44 \\
2006 & 4838 & 4.00 & 5.64 & 0.263 & 74.67 \\
2010 & 4793 & 3.61 & 5.68 & 0.269 & 74.87 \\
\hline
\end{tabular}

Fontes: Os autores, a partir Tribunal Superior Eleitoral e do Centro de Estudos da Metrópole.

Tabela 2 - Médias anuais para a dominância, número efetivo de municípios e contribuição dos 5 municípios de maior votação absoluta - Deputados federais eleitos (exceto DF), 1998-2010

\begin{tabular}{lccccc}
\hline Ano & N & Dominância & NEM & g & Cont. 5+ \\
\hline 1998 & 505 & 17.21 & 11.31 & 0.253 & 59.21 \\
2002 & 505 & 14.34 & 14.15 & 0.234 & 54.66 \\
2006 & 505 & 14.41 & 14.39 & 0.233 & 53.99 \\
2010 & 505 & 13.71 & 15.92 & 0.237 & 52.00 \\
\hline
\end{tabular}

Fontes: Os autores, a partir Tribunal Superior Eleitoral e do Centro de Estudos da Metrópole. 
${ }^{7}$ É preciso notar que estes percentuais se referem ao total de votos válidos que incluem os votos de legenda. Se considerarmos apenas os votos nominais que resultam, a rigor, das estratégias adotadas individualmente pelos candidatos, a concentração de votos é ainda mais elevada. seleção dos casos tomando por base o quociente eleitoral do estado de maior magnitude (São Paulo). Partimos do suposto simples de que, quanto maior a distância da votação do candidato com respeito ao quociente eleitoral mínimo, tanto menor a probabilidade desse candidato figurar entre aqueles com alguma chance de obter uma cadeira, e menor ainda a chance de o mesmo contribuir significativamente para a votação total do partido impactando o ordenamento da lista partidária. Assim, o quociente eleitoral de São Paulo foi dividido por quatro, obtendo-se o valor aproximado de $0,36 \%$ dos votos. Todos os candidatos com votação inferior a este número foram excluídos da base.

A linha de corte de 1/4 do quociente eleitoral de São Paulo foi estabelecida a partir da análise descritiva da contribuição dos candidatos em diferentes faixas de votação à votação total do distrito. Esta análise revelou que a distribuição de votos é altamente concentrada na imensa maioria dos estados. Na eleição de 2010, os candidatos com votação maior ou igual a $0,36 \%$ obtiveram um percentual entre $60 \%$ (São Paulo) e $91 \%$ (Tocantins) do total de votos validos do estado, sendo a média nacional igual a $83 \%{ }^{7}$. Note-se ainda que nesta eleição somente 986 dentre os 4.793 candidatos tiveram uma votação igual ou superior a 1/4 do quociente eleitoral de São Paulo. Isso quer dizer que a competição eleitoral efetiva se concentra em poucos candidatos e é sobre estes que a nossa análise dos tipos de distribuição geográfica de votação se debruça.

Para operacionalizar os tipos de votação originalmente definidos por Ames (2001), utilizamos um procedimento simples considerando a distribuição dos índices de dominância e número efetivo de municípios. Estabelecemos faixas de dominância e fragmentação alta e baixa considerando valores superiores ou inferiores a +/- 0,5 desvio-padrão da média, respectivamente. No caso específico do NEM, aplicamos uma transformação logarítmica para normalizar a distribuição, antes de estabelecer os valores das faixas. Colocamos todos os casos intermediários, com valores próximos às médias, numa categoria residual de casos não classificados. Entendemos que esse procedimento é o mais adequado tendo em vista a definição conceitual dos tipos de votação. Por exemplo, se dizemos que um candidato é concentrado, isso implica dizer que a sua distribuição de votos foge às características do candidato médio, aproximando-se do extremo inferior da distribuição; por sua vez, candidatos fragmentados teriam distribuições mais próximas do extremo superior da distribuição. Assim, candidatos cujas distribuições de dominância e número efetivo de municípios se aproximam aos extremos da distribuição tendem a se aproximar mais da definição conceitual dos tipos.

A Tabela 3 mostra a distribuição dos tipos de votação para a nossa base reduzida, com os 4.195 candidatos que obtiveram votações superiores a 1/4 do quociente eleitoral do estado de maior magnitude.

Os tipos concentrado-compartilhado e fragmentado-dominante são os mais frequentes, com cerca de $20 \%$ e $13 \%$ do total de casos respectivamente. Pouco mais da metade dos candidatos não foi classificada em nenhuma das categorias.

A Tabela 4 mostra a distribuição dos candidatos dos oito maiores partidos considerando as médias de votação nacional para a Câmara dos Deputados no período - entre os tipos de votação.

Os números em negrito indicam qual das categorias contém o maior percentual de candidatos dentre os candidatos classificados do partido. Os resultados são similares àqueles obtidos por Carvalho (2003), uma vez que os partidos de centro e direita apresentam os percentuais mais altos de participação dos candidatos de distribuição fragmentada-dominante no total. Por sua vez, PT, PSB e PDT apresentam percentuais bem mais baixos nesta última categoria; nestes partidos, predomina o tipo concentrado-compartilhado. Curiosamente, 
Tabela 3 - Distribuição dos candidatos a deputado federal segundo o tipo de distribuição geográfica dos votos, 1998-2010

\begin{tabular}{lcc}
\hline Classificação & N & \% \\
\hline Não classificados & 2146 & 51.16 \\
Concentrado-compartilhado & 863 & 20.57 \\
Fragmentado-compartilhado & 263 & 6.27 \\
Concentrado-dominante & 353 & 8.41 \\
Fragmentado-dominante & 570 & 13.59 \\
Total & 4195 & 100 \\
\hline
\end{tabular}

Fontes: Os autores, a partir Tribunal Superior Eleitoral e do Centro de Estudos da Metrópole.

Nota: Votação > $0.36 \%$ dos votos válidos.

Tabela 4 - Distribuição dos candidatos a deputado federal segundo partidos selecionados e tipo de distribuição geográfica dos votos, 1998-2010

\begin{tabular}{lccccc}
\hline Partido & Não-classificados & $\begin{array}{c}\text { Concentrado- } \\
\text { compartilhado }\end{array}$ & $\begin{array}{c}\text { Fragmentado- } \\
\text { compartilhado }\end{array}$ & $\begin{array}{c}\text { Concentrado- } \\
\text { dominante }\end{array}$ & $\begin{array}{c}\text { Fragmentado- } \\
\text { dominante }\end{array}$ \\
\hline DEM & 50.48 & 15.68 & 4.40 & 4.59 & $\mathbf{2 4 . 8 6}$ \\
PP & 51.52 & 17.88 & 3.94 & 5.76 & $\mathbf{2 0 . 9 1}$ \\
PTB & 50.43 & $\mathbf{1 8 . 2 6}$ & 8.26 & 8.70 & 14.35 \\
PSDB & 52.61 & 15.67 & 4.66 & 8.02 & $\mathbf{1 9 . 0 3}$ \\
PMDB & 52.76 & 12.27 & 4.45 & 7.98 & $\mathbf{2 2 . 5 5}$ \\
PT & 59.81 & $\mathbf{2 1 . 3 9}$ & 8.10 & 9.40 & 1.30 \\
PSB & 46.35 & $\mathbf{2 1 . 0 3}$ & 9.44 & 13.73 & 9.44 \\
PDT & 50.00 & $\mathbf{2 5 . 5 9}$ & 5.91 & 14.57 & 3.94 \\
\hline
\end{tabular}

Fontes: Os autores, a partir Tribunal Superior Eleitoral e do Centro de Estudos da Metrópole.

Nota: Votação $>0.36 \%$ dos votos válidos.

os candidatos de reduto, com votações concentradas e dominantes são mais comuns no PSB e no PDT, relativamente aos demais partidos.

A Tabela 5 mostra a evolução do percentual de candidatos de votação fragmentada e dominante por partido, ao longo das quatro eleições do período.

Os dados mostram uma rápida mudança na prevalência do tipo fragmentado-dominante entre os candidatos dos partidos à medida que estes passam da oposição para a situação, ou vice-versa. No período 1998-2002, quando compunha a base do governo FHC, o DEM obteve os percentuais mais elevados de participação de candidatos de votação fragmentada e dominante dentre todos os partidos; porém, nas eleições seguintes, com o partido já na oposição ao governo Lula, há uma queda brusca nestes percentuais. A mesma tendência pode ser observada no caso do PSDB. É interessante observar que o tipo concentrado-compartilhado se tornou prevalente para os candidatos tucanos pela primeira vez em 2010, com um total de $17,60 \%$. Neste sentido, uma vez na oposição, o PSDB tornou-se mais similar a partidos de esquerda como o PT, que teve cerca de $15 \%$ dos seus candidatos também classificados na categoria concentrado-compartilhado. Interessante notar que o PSB e o PDT viram aumentar a presença do tipo fragmentado-dominante em seus candidatos a partir da entrada no governo Lula em 2003, porém o mesmo efeito não parece ter ocorrido no caso do PT. 
Tabela 5 - Percentual de candidatos a deputado federal de votação fragmentada e dominante, por ano e partido (partidos selecionados), 1998-2010

\begin{tabular}{lcccc}
\hline Partido & $\mathbf{1 9 9 8}$ & $\mathbf{2 0 0 2}$ & $\mathbf{2 0 0 6}$ & $\mathbf{2 0 1 0}$ \\
\hline DEM & $\mathbf{2 8 . 3 4}$ & $\mathbf{3 1 . 0 3}$ & $\mathbf{2 0 . 0 0}$ & $\mathbf{1 2 . 3 5}$ \\
PP & 15.93 & $\mathbf{2 2 . 8 9}$ & $\mathbf{2 3 . 1 9}$ & $\mathbf{2 4 . 6 2}$ \\
PTB & 12.90 & 16.92 & 14.81 & 12.24 \\
PSDB & $\mathbf{2 4 . 3 8}$ & $\mathbf{2 3 . 0 8}$ & 17.60 & 7.41 \\
PMDB & $\mathbf{2 4 . 5 8}$ & $\mathbf{2 3 . 9 3}$ & $\mathbf{1 9 . 3 0}$ & $\mathbf{2 2 . 3 0}$ \\
PT & 0.00 & 1.10 & 1.28 & 2.67 \\
PSB & 11.90 & 1.61 & 9.86 & $\mathbf{1 5 . 5 2}$ \\
PDT & 3.17 & 1.61 & 1.45 & 10.00 \\
\hline
\end{tabular}

Fontes: Os autores, a partir Tribunal Superior Eleitoral e do Centro de Estudos da Metrópole.

Em síntese, os dados fornecem uma primeira indicação da existência de um efeito da clivagem governo-oposição sobre a geografia do voto nas eleições para a Câmara dos Deputados. Na seção seguinte, desenvolvemos testes que permitem quantificar de forma mais precisa a magnitude desses efeitos, por meio de análise de regressão multivariada.

III.1. Determinantes da fragmentação e dominância dos candidatos a deputado federal: análises multivariadas

Apresentamos, nesta seção, uma série de modelos de regressão linear com o objetivo de testar as nossas hipóteses sobre os determinantes dos padrões de votação dos candidatos à Câmara Federal. Pelas razões já expostas na seção anterior, utilizamos a base de dados reduzida, com os 4.195 candidatos de votação superior a $0,36 \%$ dos votos válidos. Do total de 4.195 casos, perdemos quatro observações em razão de problemas na base do TSE. Os testes realizados com toda a base de 16.993 candidatos, incluindo uma variável dummy para controlar por faixas de votação, produziram resultados semelhantes aos obtidos, o que nos assegura da ausência de vieses nas inferências. As variáveis dependentes dos modelos são a dominância municipal (domin) e o logaritmo do número efetivo de municípios (NEM) para a votação dos candidatos (lfrag). Em todos os modelos colocamos a dominância como função do número efetivo de partidos, e esta última variável como função da dominância, de modo a obter estimativas de fragmentação (dominância) controlando pelos níveis de dominância (fragmentação).

As principais variáveis explicativas são as dummies para o posicionamento dos partidos frente aos governos federal e estadual: govcoalizão, indicando candidato filiado a partido de governador membro da coalizão governista nacional; coalizão, que indica candidato cujo partido é membro da coalizão, mas não controla a governador; e governador, para candidatos filiados ao partido de governador que não participa da da coalizão de apoio ao presidente. Incluímos ainda uma dummy para candidatos incumbentes concorrendo à reeleicão (incumbente). O efeito esperado para todas estas dummies sobre as variáveis dependentes é positivo. Candidatos incumbentes e candidatos situacionistas tendem a obter níveis mais altos de fragmentação e dominância, tudo o mais mantido constante. Além disso, é nossa expectativa que os efeitos de govcoalizão sobre a dominância e o NEM sejam mais fortes do que os estimados para coalizão e governador, dada a nossa hipótese sobre o efeito cumulativo do acesso aos recursos do executivo federal e estadual simultaneamente.

Para testar a hipótese de que candidatos situacionistas têm maiores chances de desenvolver padrões de votação de tipo fragmentado-dominante, intera- 
gimos as dummies govcoalizão, coalizão e governador com a medida de fragmentação. A expectativa é de que o sinal das interações seja positivo, indicando que o impacto do acesso aos recursos do executivo sobre a dominância é mais forte quanto mais altos forem os níveis de fragmentação da votação. $\mathrm{O}$ mesmo procedimento foi adotado nos modelos tendo o logaritmo do NEM como variável dependente: interagimos as dummies de participação nos governos estadual e federal com a medida de dominância. Também é nossa expectativa de que haveria um efeito estatisticamente relevante e positivo dos termos interativos: quanto maior a dominância, mais forte o efeito positivo das dummies sobre a fragmentação.

Para dar conta dos efeitos independentes da organização e ideologia partidária sobre os padrões de votação típicos dos candidatos, incluímos uma variável binária para candidatos filiados a partidos de esquerda. A nossa expectativa é que o efeito principal deste indicador seja negativo sobre a dominância e a fragmentação. Interagimos ainda a variável binária esquerda com o logaritmo do NEM e com a dominância. Esperamos que o efeito da interação seja negativo. Isto é, que o efeito negativo da ideologia de esquerda sobre a dominância (fragmentação) seja mais forte quanto maiores os níveis de fragmentação (dominância).

Como controles, os modelos incluem os anos eleitorais (base $=1998$ ), para controlar flutuações temporais nos níveis médios de dominância e fragmentação, e dummies para as grandes regiões brasileiras para dar conta de possíveis efeitos de diferenças inter-regionais de ordem demográfica, social e política, sobre os padrões de votação.

Uma possível fonte de endogenia dos modelos encontra-se no fato de que partidos grandes têm maior probabilidade de eleger governadores e integrar gabinetes presidenciais do que partidos pequenos. Assim, parte do efeito das medidas de participação nos governos estadual e federal pode ser atribuído às vantagens competitivas dos partidos grandes em termos de acesso a recursos de campanha, fundo partidário, tempo de TV etc. Uma vez que a construção e manutenção de distritos informais de tipo fragmentado e dominante exige investimento expressivo de recursos de campanha, é de se imaginar que candidatos filiados a partidos maiores tenham maiores chances de sucesso nessa empreitada. Assim, criamos duas dummies de controle para partidos grandes (votação nacional superior a 10\% nas eleições para deputado federal) e partidos médios (votação entre $4 \%$ e 9,99\%). Os percentuais foram classificados considerando a média das duas eleições realizadas antes do primeiro ano da série (1990 e 1994), uma vez que o tamanho dos partidos a partir de 1998 também tende a estar relacionado às variáveis explicativas, como participação na coalizão federal.

Por fim, introduzimos como controle o número de municípios de cada estado, para dar conta dos efeitos das características das redes urbanas estaduais sobre as estratégias dos candidatos. Em regra, estados com mais municípios são mais populosos e extensos territorialmente, o que tem implicações do ponto de vista das estratégias eleitorais mais eficazes.

A seguir são apresentados os modelos estimados para a dominância municipal. Para facilitar a leitura, as variáveis de controle foram omitidas das tabelas (Tabela 6).

O modelo 1A é o modelo base, sem os termos interativos. Nesta primeira regressão, obtivemos resultados congruentes com as expectativas teóricas. $\mathrm{Na}$ média, candidatos situacionaistas têm maior probabilidade de obter votações dominantes, mantida constante a fragmentação. Este efeito é, como esperado, mais forte para candidatos filiados a partidos de governadores da coalizão do 
Tabela 6 - Determinantes da dominância municipal dos candidatos a deputado federal, 1998-2010

\begin{tabular}{|c|c|c|c|c|c|c|c|c|c|}
\hline & \multicolumn{3}{|c|}{ Modelo 1A } & \multicolumn{3}{|c|}{ Modelo 1B } & \multicolumn{3}{|c|}{ Modelo 1C } \\
\hline & B & Erro & $\mathbf{p}$ & B & Erro & $\mathbf{p}$ & B & Erro & $\mathbf{p}$ \\
\hline (Intercept) & 0.46 & 1.18 & 0.70 & 1.74 & 1.21 & 0.15 & -0.42 & 1.22 & 0.73 \\
\hline esquerda & $* * *-1.91$ & 0.34 & 0.00 & $* * *-1.99$ & 0.34 & 0.00 & $* * * 2.75$ & 0.64 & 0.00 \\
\hline govcoalizão & $* * * 2.88$ & 0.51 & 0.00 & -0.89 & 1.05 & 0.40 & 0.46 & 1.06 & 0.66 \\
\hline governador & $* * * 2.39$ & 0.86 & 0.01 & 2.02 & 1.87 & 0.28 & 1.82 & 1.85 & 0.32 \\
\hline coalizão & $* * * 1.70$ & 0.36 & 0.00 & -0.47 & 0.67 & 0.48 & 0.37 & 0.67 & 0.59 \\
\hline lfrag & $* * * 0.50$ & 0.18 & 0.00 & $*_{-}-0.55$ & 0.29 & 0.06 & $* * 0.63$ & 0.32 & 0.05 \\
\hline incumbente & $* * * 2.13$ & 0.34 & 0.00 & $* * * 2.08$ & 0.33 & 0.00 & $* * * 1.94$ & 0.33 & 0.00 \\
\hline $\begin{array}{l}\text { lfrag x } \\
\text { govcoalizão }\end{array}$ & - & - & - & $* * * 2.09$ & 0.48 & 0.00 & $* * * 1.39$ & 0.48 & 0.00 \\
\hline $\begin{array}{l}\text { lfrag x } \\
\text { coalizão }\end{array}$ & - & - & - & $* * * 1.35$ & 0.35 & 0.00 & $* * * 0.91$ & 0.35 & 0.01 \\
\hline $\begin{array}{l}\text { lfrag x } \\
\text { governador }\end{array}$ & - & - & - & 0.40 & 0.89 & 0.65 & 0.38 & 0.88 & 0.66 \\
\hline \multirow{3}{*}{$\begin{array}{l}\text { lfrag x } \\
\text { esquerda }\end{array}$} & - & - & - & - & - & - & $* * *-2.91$ & 0.34 & 0.00 \\
\hline & $\mathrm{N}$ & 4191 & & $\mathrm{~N}$ & 4191 & & $\mathrm{~N}$ & 4191 & \\
\hline & $\mathrm{R} 2$ & 0.134 & & $\mathrm{R} 2$ & 0.138 & & $\mathrm{R} 2$ & 0.153 & \\
\hline
\end{tabular}

Fonte: Os autores.

presidente. É interessante observar que o efeito estimado para candidatos filiados ao partido de um governador de situação em relação ao governo federal é mais forte do que aquele estimado para membros da coalizão nacional que não controlam a governadoria. Esta é uma primeira evidência em favor do nosso argumento sobre a importância da conexão estadual nas eleições legislativas federais.

O segundo modelo introduz as interações entre lfrag, govcoalizão, governador e coalizão. Os termos interativos para as dummies govcoalizão, coalizão e governador são positivos, porém os efeitos da interação para esta última variável são estatisticamente irrelevantes. Os testes estatísticos que realizamos demonstram que os efeitos marginais do controle das governadorias sobre a dominância são fracos: a reta de valores previstos para o termo interativo, estabelecendo valor 1 para governador e zero para govcoalizão e coalizão, é quase paralela ao eixo $\mathrm{x}$.

O terceiro modelo (1C) inclui a interação entre esquerda e lfrag. Note-se que nesta especificação, o coeficiente estimado para lfrag indica o impacto do número efetivo de municípios sobre a dominância quando esquerda $=0$. Portanto, o coeficiente positivo para a fragmentação indica que no caso dos candidatos de centro e direita, há uma associação positiva entre fragmentação e dominância. O sinal negativo para o termo interativo esquerda*lfrag indica que o efeito é exatamente o oposto para candidatos de esquerda.

Neste último modelo, os efeitos das interações entre o número efetivo de municípios e as dummies govcoalizão e coalizão são mais fracos relativamente ao modelo 1B. Muito provavelmente, parte da diferença entre os valores de dominância municipal para candidatos governistas e não-governistas estimados no modelo 1B decorre de diferenças entre partidos de esquerda e direita. Uma vez que a participação dos partidos de esquerda na oposição ao governo federal foi mais frequente relativamente aos partidos de centro e direita no período em 
8 Vale lembrar que o logaritmo de 1 é igual a zero. Candidatos com NEM entre 1 e 2 estão situados entre 0 e 0.67 na escala do gráfico. análise, o efeito de ser de oposição pode se confundir com o efeito de ser filiado a um partido de esquerda. Apesar disso, o efeito de govcoalizão permanece relevante e estatisticamente significativo neste último modelo. O Gráfico 1 mostra os efeitos marginais para todo o espectro de valores do número efetivo de municípios. Ele indica a diferença entre os valores de dominância médios estimados para um candidato filiado ao partido de um governador da coalizão presidencial e para um outro de oposição ao governo federal, não filiado ao partido do governador. Essas diferenças estão plotadas a cada valor do número efetivo de municípios (aqui tabulado em uma escala logarítmica), juntamente com os intervalos de confiança:

O Gráfico 2 mostra o efeito marginal da ideologia de esquerda sobre a dominância, para todos os valores do logaritmo do número efetivo de municípios.

Como se vê, o efeito da ideologia partidária é significativo para todo o arco de valores do número efetivo de municípios, cujos logaritmos variam de 0 a 4,75. É interessante notar que, para distribuições muito concentradas, próximas de zero no eixo $\mathrm{x}$, o efeito da ideologia de esquerda é positivo, sendo negativo para todo o resto da distribuição ${ }^{8}$.

Para determinar com maior clareza os efeitos combinados da ideologia partidária e do posicionamento dos partidos com respeito ao Poder Executivo no plano federal e estadual realizamos algumas simulações simples a partir do modelo 1C. A Tabela 7 mostra os valores de dominância previstos para candidatos de esquerda e de centro/direita em pontos extremos da escala de fragmentação (primeiro e nono decis), contrastando candidatos filiados a partidos de

Gráfico 1 - Efeito marginal da filiação a partido governista no plano estadual (governador) e federal sobre a dominância municipal (modelo 1C)

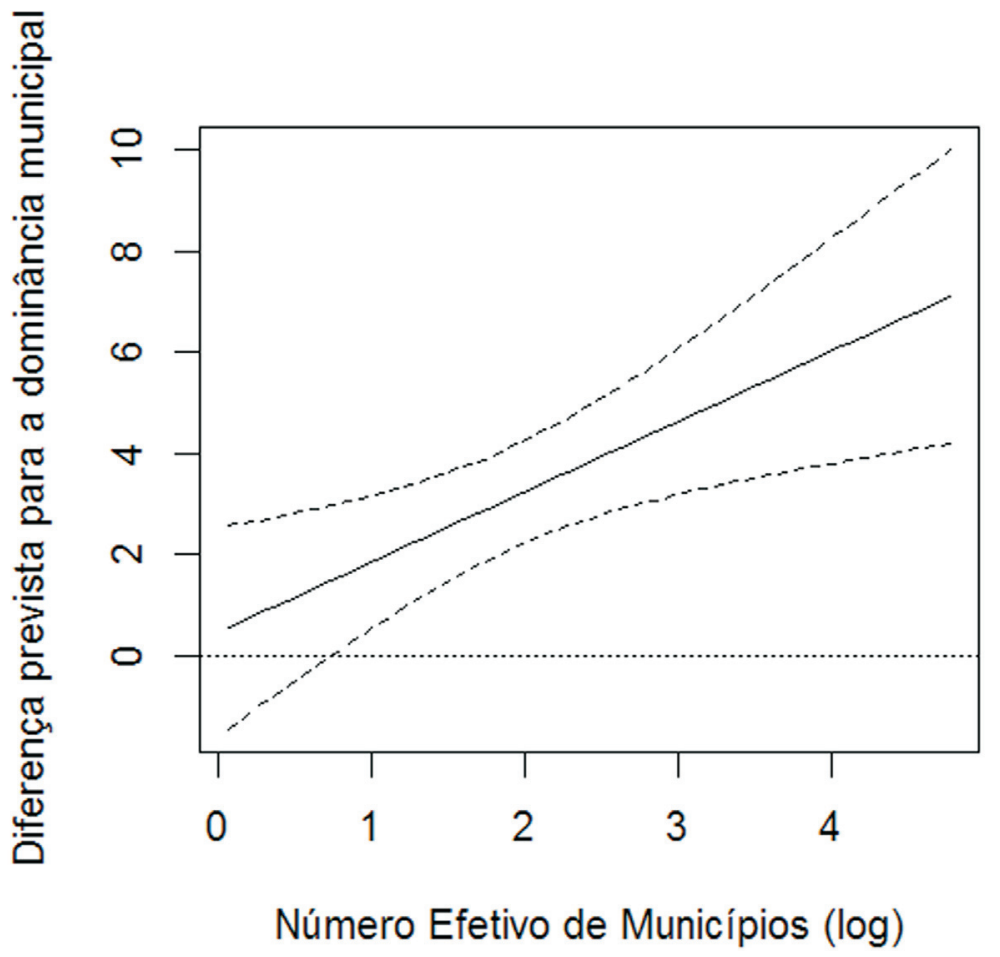

Fonte: Os autores. 
Gráfico 2 - Efeito marginal da ideologia de esquerda sobre a dominância municipal (modelo 1C)

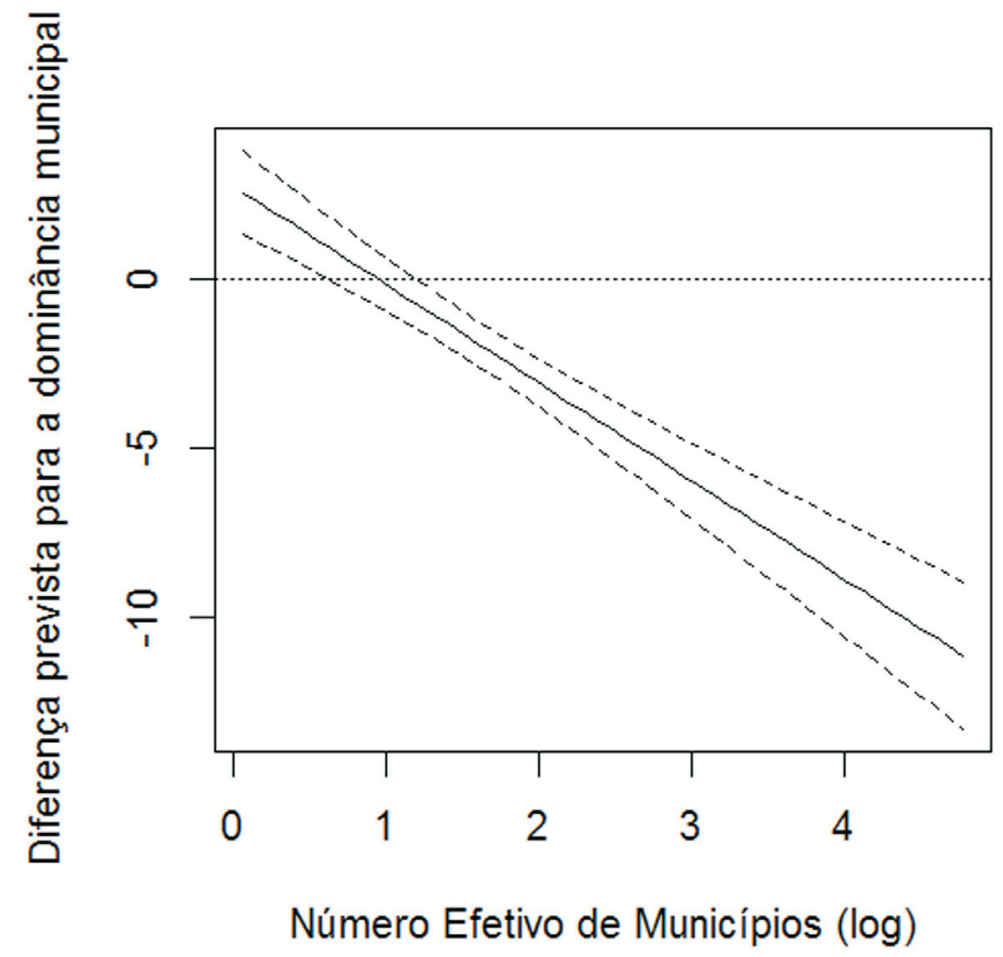

Fonte: Os autores.

Tabela 7 - Valores de dominância previstos para diferentes categorias de ideologia partidária e participação nos governos federal e estadual, $9^{\circ}$ e $1^{\circ}$ decil do número efetivo de municípios (modelo 1C)

\begin{tabular}{lcclcc}
\hline Ideologia & \multicolumn{2}{c}{$\mathbf{9}^{\mathbf{0}}$ decil } & & \multicolumn{2}{c}{$\mathbf{1}^{\mathbf{0}}$ decil } \\
\cline { 2 - 3 } \cline { 5 - 6 } \cline { 5 - 6 } & $\begin{array}{c}\text { Governador } \\
\text { coalizão }\end{array}$ & $\begin{array}{c}\text { Categoria } \\
\text { base }\end{array}$ & & $\begin{array}{c}\text { Governador } \\
\text { coalizão }\end{array}$ & $\begin{array}{c}\text { Categoria } \\
\text { base }\end{array}$ \\
\hline Esquerda & 11.28 & 7.34 & & $\mathbf{1 3 . 0 4}$ & 11.89 \\
Centro/Direita & $\mathbf{1 5 . 8 9}$ & 11.86 & & 11.74 & 10.59 \\
\hline
\end{tabular}

Fonte: Os autores.

governadores da base governista e candidatos de oposição não filiados ao partido do governador (categoria base).

Os valores em negrito indicam os maiores índices de dominância previstos para cada um dos decis do NEM utilizados na simulação. Os resultados mostram que candidatos de esquerda governistas apresentam, na média, índices de dominância maiores que candidatos de centro ou direita também governistas nas faixas extremas de concentração; porém, para distribuições muito fragmentadas, a vantagem se inverte em favor dos candidatos de centro/direita.

Apresentamos, na Tabela 8, os modelos estimados para o Número Efetivo de Municípios. Uma vez que a variável dependente foi transformada no seu logaritmo natural, a interpretação dos coeficientes e efeitos marginais é um 
Tabela 8 - Determinantes do número efetivo de municípios, candidatos a deputado federal, 1998-2010

\begin{tabular}{|c|c|c|c|c|c|c|c|c|c|}
\hline & \multicolumn{3}{|c|}{ Modelo 2A } & \multicolumn{3}{|c|}{ Modelo 2B } & \multicolumn{3}{|c|}{ Modelo 2C } \\
\hline & B & Erro & $\mathbf{p}$ & B & Erro & $\mathbf{p}$ & B & Erro & p \\
\hline (Intercept) & -0.19 & 0.10 & 0.07 & -0.11 & 0.10 & 0.30 & -0.199 & 0.103 & 0.054 \\
\hline esquerda & $* * *_{-} 0.29$ & 0.03 & 0.00 & $* * *-0.29$ & 0.03 & 0.00 & -0.053 & 0.043 & 0.211 \\
\hline govcoalizão & $* * * 0.28$ & 0.04 & 0.00 & 0.03 & 0.07 & 0.64 & $* 0.129$ & 0.073 & 0.075 \\
\hline governador & $* * * 0.28$ & 0.08 & 0.00 & 0.17 & 0.12 & 0.17 & 0.190 & 0.123 & 0.124 \\
\hline coalizão & $* * * 0.18$ & 0.03 & 0.00 & 0.05 & 0.04 & 0.25 & $* * 0.115$ & 0.045 & 0.012 \\
\hline domin & $* * * 0.00$ & 0.00 & 0.00 & $* *-0.01$ & 0.00 & 0.02 & $* * 0.006$ & 0.003 & 0.033 \\
\hline incumbente & $* * * 0.48$ & 0.03 & 0.00 & $* * * 0.47$ & 0.03 & 0.00 & $* * * 0.455$ & 0.028 & 0.000 \\
\hline $\begin{array}{l}\text { domin } x \\
\text { govcoalizão }\end{array}$ & - & - & - & $* * * 0.02$ & 0.00 & 0.00 & $* * * 0.011$ & 0.004 & 0.008 \\
\hline $\begin{array}{l}\text { domin } x \\
\text { coalizão }\end{array}$ & - & - & - & $* * * 0.01$ & 0.00 & 0.00 & $* * 0.006$ & 0.003 & 0.048 \\
\hline $\begin{array}{l}\text { domin } \mathrm{x} \\
\text { governador }\end{array}$ & - & - & - & 0.01 & 0.01 & 0.18 & 0.009 & 0.008 & 0.254 \\
\hline \multirow{3}{*}{$\begin{array}{l}\text { domin } x \\
\text { esquerda }\end{array}$} & - & - & - & - & - & - & $* * *-0.022$ & 0.003 & 0.000 \\
\hline & $\mathrm{N}$ & 4191 & & $\mathrm{~N}$ & 4191 & & $\mathrm{~N}$ & 4191 & \\
\hline & $\mathrm{R} 2$ & 0.322 & & $\mathrm{R} 2$ & 0.326 & & $\mathrm{R} 2$ & 0.335 & \\
\hline
\end{tabular}

Fontes: Os autores, a partir Tribunal Superior Eleitoral e do Centro de Estudos da Metrópole.

pouco mais complexa relativamente aos modelos anteriores. De modo geral, porém, os resultados são muito semelhantes.

Em consonância com as nossas hipóteses, os efeitos "puros” da participação nos governos federal e estadual são positivos sobre a fragmentação (modelo 2A). Controlar a governadoria tem um efeito mais forte sobre a fragmentação, para valores médios de dominância, do que ser membro da coalizão do presidente, o que pode ser deduzido das diferenças entre os coeficientes estimados para governador e coalizão. As interações entre a dominância municipal e as dummies govcoalizão e coalizão são significativas e positivas (modelo 2B), o que indica uma associação positiva entre dominância e fragmentação para candidatos da base governista no plano nacional. Este efeito não está presente para candidatos filiados a partidos de governadores de oposição, exatamente como no modelo estimado para a dominância (1B). O terceiro modelo (2C) mostra, por sua vez, que o efeito da dominância sobre o número efetivo de municípios é negativo para os partidos de esquerda. Vale notar que o todos os modelos apresentam um $\mathrm{R}^{2}$ superior a 0,30 , o que indica um ajuste melhor relativamente àqueles estimados para a dominância 9 .

${ }^{9}$ Essas diferenças se explicam em parte por conta da forte correlação entre o logaritmo do número de municípios e o NEM, que é de cerca de 0,40 ; o coeficiente de correlação entre a dominância e esta variável de controle é de 0,26.

${ }^{10}$ Em razão as características da distribuição log-normal, o anti-logaritmo de $\mathrm{Y}$ dado o vetor de variáveis independentes $\mathrm{x} 1, \mathrm{x} 2, \mathrm{x} 3 \ldots \mathrm{xk}$,
Dada a transformação da variável dependente, torna-se mais difícil interpretar o significado das interações no modelo $2 \mathrm{C}$. Uma forma mais simples de interpretar os termos interativos é por meio da simulação dos efeitos combinados da ideologia partidária e do posicionamento dos partidos com respeito ao Poder Executivo no plano federal e estadual sobre a fragmentação (Tabela 9). Vale notar que a conversão dos valores previstos em termos da escala logarítmica para a escala original requer uma correção, considerando o valor do erro quadrado médio ${ }^{10}$.

A simulação mostra que tanto para valores altos quanto baixos de dominância, candidatos de partidos de centro ou direita sempre apresentam índices de fragmentação mais altos do que candidatos de esquerda. Supondo dois candi- 
é igual à mediana da distribuição condicional de Y. Para calcular o valor esperado ou valor médio, é preciso utilizar a fórmula exp[(Y $\mathrm{Bx})+1 / 2 \mathrm{EQM}]$ sendo EQM o erro quadrado médio do modelo de regressão.
Tabela 9 - Valores do número efetivo de municípios previstos para diferentes categorias de ideologia partidária e participação nos governos federal e estadual, $9^{\circ}$ e $1^{\circ}$ decil do número efetivo de municípios (modelo 1C)

\begin{tabular}{lcclccc}
\hline Ideologia & \multicolumn{2}{c}{$\mathbf{9}^{\mathbf{0}}$ decil } & & \multicolumn{2}{c}{$\mathbf{1}^{\mathbf{0}}$ decil } \\
\cline { 2 - 3 } \cline { 5 - 6 } \cline { 5 - 6 } & $\begin{array}{c}\text { Governador } \\
\text { coalizão }\end{array}$ & $\begin{array}{c}\text { Categoria } \\
\text { base }\end{array}$ & & $\begin{array}{c}\text { Governador } \\
\text { coalizão }\end{array}$ & $\begin{array}{c}\text { Categoria } \\
\text { base }\end{array}$ \\
\hline Esquerda & 6.93 & 4.52 & & 7.87 & 6.80 \\
Centro/Direita & $\mathbf{1 3 . 1 7}$ & 8.60 & & $\mathbf{8 . 6 0}$ & 7.43 \\
\hline
\end{tabular}

Fonte: Os autores.

datos posicionados no $9^{\circ}$ decil de dominância, membros da base do governo federal e filiados ao partido do governador, espera-se que o candidato de esquerda tenha um índice de fragmentação correspondente a pouco mais da metade daquele previsto para o candidato de centro ou direita $(13,17$ x 6,93). Vale notar que candidatos de esquerda governistas na faixa extrema de dominância apresentam tanta capacidade dispersar seus votos quanto candidatos de mesma ideologia, porém de oposição, no $1^{\circ}$ decil de dominância $(6,93$ x 6,80). Esses resultados indicam que a associação positiva que postulamos entre dominância e fragmentação para os candidatos governistas se verifica no grupo de candidatos de centro ou direita, porém não no interior do grupo de candidatos de esquerda.

Resta saber se os efeitos relativos ao posicionamento dos partidos com respeito ao Poder Executivo no plano federal e estadual persistem quando comparamos a capacidade de candidatos estreantes e postulantes à reeleição dominarem os seus redutos. Argumentamos que há uma diferença central entre os presidencialismos brasileiro e norte-americano que nos obriga a relativizar a formulação original da teoria distributivista. A capacidade dos candidatos à reeleição de dominar seus municípios-chave depende fundamentalmente da participação na coalizão de governo, sendo as vantagens intrínsecas ao cargo de deputado federal de menor relevância para explicar essa dimensão.

Para testar essa hipótese desenvolvemos um modelo de regressão linear multivariado que com interações entre as dummies que mensuram o posicionamento dos partidos com respeito aos governos estadual e federal e a dummy que indica o status do candidato (incumbente). A grande vantagem dessa especificação é que, com a inserção dos termos interativos, o coeficiente estimado para a variável incumbente passa a indicar o efeito da incumbência para candidatos de oposição não filiados ao partido do governador. Por sua vez, os coeficientes para as dummies govcoalizão, coalizão, e governador indicam o efeito de cada uma destas variáveis quando incumbente assume valor zero; isto é, o impacto da participação nos governos federal e estadual sobre a dominância de candidatos estreantes, sem mandato de deputado federal.

Em uma segunda especificação do modelo, incluímos uma interação entre incumbência e fragmentação com o intuito de verificar se há diferença no ganho esperado de dominância dos candidatos à reeleição a depender do grau de dispersão ou concentração de votos.

A Tabela 10 apresenta os resultados das duas especificações.

Os coeficientes estimados para os termos interativos do modelo $3 \mathrm{~A}$ indicam que candidatos à reeleição cujos partidos são membros do gabinete presidencial apresentam, na média, taxas de dominância cerca de $\mathbf{1 . 3}$ pontos percentuais mais altas do que candidatos estreantes também filiados a partidos governistas (coeficiente para coalizão $\mathrm{x}$ incumbente menos o coeficiente para coalizão). $\mathrm{O}$ 
Tabela 10 - Estimação dos efeitos combinados da incumbência e participação nos governos federal e estadual sobre a dominância municipal, 1998-2010

\begin{tabular}{|c|c|c|c|c|c|c|}
\hline & \multicolumn{3}{|c|}{ Modelo 3A } & \multicolumn{3}{|c|}{ Modelo 3B } \\
\hline & B & Erro & $\mathbf{p}$ & B & Erro & $\mathbf{p}$ \\
\hline (Intercept) & 0.69 & 1.18 & 0.56 & 2.06 & 1.18 & 0.08 \\
\hline esquerda & $* * *-1.90$ & 0.34 & 0.00 & $* * *-1.74$ & 0.33 & 0.00 \\
\hline govcoalizão & $* * * 2.73$ & 0.66 & 0.00 & $* * * 3.23$ & 0.65 & 0.00 \\
\hline governador & $* * 2.44$ & 1.06 & 0.02 & $* * * 2.76$ & 1.05 & 0.01 \\
\hline coalizão & $* * 0.97$ & 0.43 & 0.02 & $* * * 1.27$ & 0.42 & 0.00 \\
\hline lfrag & $* * * 0.49$ & 0.18 & 0.01 & $* * *-0.59$ & 0.21 & 0.01 \\
\hline incumbente & 0.78 & 0.60 & 0.20 & $* * *-4.15$ & 0.82 & 0.00 \\
\hline govcoalizão $\mathrm{x}$ incumbente & 0.94 & 1.00 & 0.34 & -0.34 & 1.00 & 0.73 \\
\hline coalizão x incumbente & $* * * 2.25$ & 0.73 & 0.00 & $* 1.43$ & 0.73 & 0.05 \\
\hline governador $\mathrm{x}$ incumbente & 0.24 & 1.79 & 0.89 & -0.88 & 1.78 & 0.62 \\
\hline \multirow[t]{3}{*}{ lfrag $x$ incumbente } & - & - & - & $* * * 2.84$ & 0.33 & 0.00 \\
\hline & $\mathrm{N}$ & 4.191 & & $\mathrm{~N}$ & 4.191 & \\
\hline & $\mathrm{R} 2$ & 0.135 & & $\mathrm{R} 2$ & 0.150 & \\
\hline
\end{tabular}

Fontes: Os autores, a partir Tribunal Superior Eleitoral e do Centro de Estudos da Metrópole e Câmara dos Deputados.

efeito da dummy incumbente é positivo, porém sem significância estatística. Isso implica dizer que, na média, candidatos incumbentes de oposição ao governo federal e não filiados ao partido do governador não possuem nenhuma vantagem em relação a candidatos estreantes no que diz respeito à capacidade obter votações dominantes. As interações entre incumbente e as dummies governador e govcoalizão não são significativas, muito embora os efeitos principais para estas duas últimas variáveis sejam fortes e positivos. De modo geral, o modelo indica que, para os candidatos incumbentes, o que realmente garante uma vantagem competitiva é fazer parte da coalizão governista no plano nacional. Por outro lado, para os candidatos estreantes, ser filiado ao partido do governador tem o efeito mais relevante, dado que os efeitos para governador $\mathrm{e}$ govcoalizão são bem maiores do que aqueles estimados para coalizão $(2,73$ e $2,44 \times 0,97)$.

Estes resultados fazem sentido se pensarmos que os deputados federais contam com melhores oportunidades de acesso aos recursos controlados pelos ministérios através de atividades de pork e intermediação de demandas. De fato, a construção de maiorias legislativas na Câmara Federal passa exatamente pela concessão de benefícios de pork e "bens de coalizão" (coalition goods) aos partidos governistas (Raile, Pereira \& Power 2011). Por sua vez, candidatos estreantes que ocupam cargos na esfera estadual, como deputado ou secretário de governo, estão em melhores condições de se beneficiar do apoio do governador do que colegas de partido que cumprem mandato de deputado federal em Brasília. Em certo sentido, o forte efeito da filiação ao partido do governador sobre a dominância é congruente com os achados de pesquisas anteriores que demonstram a importância da passagem por postos subnacionais como porta de entrada para o legislativo federal no Brasil.

O segundo modelo inclui uma interação entre fragmentação e a dummy incumbente, o que nos permite verificar possíveis variações nos ganhos médios de dominância para candidatos à reeleição para diferentes níveis de concentração de votos. A seguir apresentamos os valores de dominância previstos para candidatos incumbentes integrantes e não integrantes da coalizão presidencial, 
e comparamos estas previsões com aquelas realizadas para candidatos estreantes da coalizão, filiados ao partido do governador, para os percentis 10 e 90, e mediana do número efetivo de municípios. Os valores em itálico indicam as diferenças estatisticamente significativas que indicam vantagem competitiva dos candidatos estreantes; em negrito, o resultado da simulação em que se verifica vantagem para os incumbentes (Tabela 11).

A Tabela 11 confirma que candidatos incumbentes de oposição, não filiados ao partido do governador, apresentam menor capacidade de dominar seus redutos relativamente a candidatos estreantes de situação (i.e., para govcoalizão =1). Porém na faixa extrema de fragmentação (percentil 90), não há diferenças expressivas entre incumbentes e estreantes. Além disso, as diferenças entre (2) e (3) na tabela indicam que, para valores baixos de fragmentação (percentil 10), ser filiado ao partido do governador garante uma vantagem para candidatos estreantes de situação em relação a um candidato incumbente também da base do governo. Possuir mandato legislativo só garante um ganho de dominância para candidatos fragmentados (percentil 90).

\section{Conclusões}

O objetivo do artigo consistiu em buscar um novo caminho analítico no que diz respeito aos determinantes dos padrões de votação dos candidatos à Câmara Federal no Brasil. A partir da dicotomia básica situação/oposição, desenvolvemos uma matriz de posicionamento dos partidos frente aos governos estadual e federal de modo a explicar segmentações distintas na geografia dos votos dos deputados. A nossa hipótese central é que candidatos situacionistas (em ambas as esferas) apresentariam um padrão de votação caracterizado por índices de dominância e fragmentação elevados, diferente dos deputados oposicionistas, cujas votações tenderiam a ser compartilhadas e/ou concentradas. A análise multivariada indica, de fato, que o efeito do posicionamento frente aos governos federal e estadual tem grande peso sobre os padrões de geografia do voto e que o tipo fragmentado-dominante se associa fortemente aos candidatos mais situacionistas.

Contudo, o corte ideológico - esquerda x centro/direita - se mostrou extremamente significativo. Candidatos de esquerda concentrados apresentam probabilidade muito maior de desenvolver votações dominantes do que candidatos fragmentados. No entanto, entre os candidatos de partidos de centro e direita o oposto é verdadeiro: candidatos fragmentados desenvolvem em média, votações mais dominantes do que candidatos concentrados. Estas diferenças se mantêm inclusive no interior do grupo de candidatos de situação. Possivelmente, esse resultado deriva de uma maior rigidez do processo de recrutamento

Tabela 11 - Valores de dominância municipal para candidatos incumbentes x estreantes, conforme a participação nos governos federal e estadual, percentis 10, 90 e mediana do número efetivo de municípios (modelo 3B)

\begin{tabular}{lccc}
\hline & \multicolumn{3}{c}{ Percentis } \\
\cline { 2 - 4 } & $\mathbf{1 0}$ & $\mathbf{5 0}$ & $\mathbf{9 0}$ \\
\hline (1) Incumbente (categoria base) & 8.20 & 10.76 & 12.70 \\
(2) Incumbente (coalizão) & 10.90 & 13.46 & 15.40 \\
(3) Estreante (governador coalizão) & 14.16 & 13.49 & 12.98 \\
Diferença (1) - (3) & $-5.97 * * *$ & $-2.73 * * *$ & -0.27 \\
Diferença (2)-(3) & $-3.31 * * *$ & -0.03 & $2.40 * * *$ \\
\hline
\end{tabular}

Fonte: Os autores 
${ }^{11}$ Desse modo, parte das diferenças encontradas entre os candidatos de esquerda e de centro ou direita talvez se devam a uma maior propensão dos partidos de esquerda a perseguir estratégias policy-seeking, evitando apoiar governos de partidos adversários no plano estadual. dos partidos de esquerda, o que tornaria mais lentas ou improváveis mudanças nos padrões de votação decorrentes da passagem da oposição para situação.

Vale notar, por outro lado, que os resultados dos modelos, especialmente no que diz respeito às diferenças encontradas entre candidatos de oposição e os demais devem ser analisados com certo cuidado, em função da limitação dos dados. Não temos informações sobre as coalizões governativas formadas em nível estadual e, por isso, a categoria base do modelo - partidos que não controlam nem a governadoria e nem participam da coalizão do presidente inclui candidatos que, a rigor, são situação no plano estadual ${ }^{11}$.

Contrariamente aos pressupostos da teoria distributivista, demonstramos que o efeito da incumbência sobre a capacidade dos candidatos de dominar seus municípios-chave é menos relevante do que as vantagens advindas do acesso aos recursos controlados pelo Poder Executivo na esfera federal. Em outras palavras, no Brasil a dependência frente ao Executivo faz com que as vantagens intrínsecas ao cargo de deputado federal sejam insuficientes para garantir a manutenção de bases eleitorais dominantes. Ao contrário, candidatos incumbentes concentrados, incluindo aqueles que participam da base do governo federal, apresentam desvantagem com respeito a estreantes também situacionistas. Este resultado nos permite intuir que o ambiente institucional em que operam os candidatos à reeleição é refratário à consolidação de bases concentradas e dominantes, que seriam o análogo do distrito majoritário dos candidatos ao congresso norte-americano.

As evidências apresentadas neste artigo também demonstram a importância da arena política estadual para as estratégias eleitorais dos candidatos à Câmara dos Deputados. Em especial, ser filiado ao partido do governador aumenta significativamente a chance de um candidato estreante desenvolver votação dominante. Entretanto, para candidatos incumbentes integrar o partido do governador não garante ganhos de dominância em relação a um estreante em igual situação. Esses resultados sugerem que o acesso aos cargos e verbas controlados pelos governos estaduais tem peso muito importante na construção de novas candidaturas à Câmara Federal. Possivelmente, isso ocorre principalmente em razão da relevância da ocupação de cargos no legislativo e executivo subnacional para as carreiras dos políticos brasileiros (Samuels 2003; Bourdoukan 2006; Santana 2008; Lima 2013).

De modo geral, os resultados da pesquisa apontam no sentido da matização dos argumentos relativos ao personalismo e ao paroquialismo como elementos centrais da conexão eleitoral no Brasil. Em que pesem os incentivos às estratégias individualistas de campanha gerados pelo sistema proporcional de lista aberta, a preponderância do Poder Executivo no presidencialismo brasileiro coloca como importante eixo da competição política nas eleições legislativas o acesso às coalizões governativas nacionais e estaduais. Com isso, torna-se muito implausível supor que as decisões tomadas pelos candidatos à Câmara, inclusive aquelas relativas às suas estratégias de campanha, sejam tomadas de forma independente das decisões tomadas por presidentes, governadores e pelos partidos políticos na arena eleitoral e governativa. Vale notar, por fim, que as coalizões construídas no plano nacional e estadual seguem uma lógica que é, em última análise, partidária. Assim, dizer que as coalizões de governo impactam a geografia do voto é também dizer que as trajetórias dos parlamentares não se dissociam completamente da trajetória dos seus partidos. 
André Borges (andrebc@unb.br) é Doutor em Ciência Política pela Universidade de Oxford (Reino Unido) e professor do Instituto de Ciência Política da Universidade de Brasília (Unb). Vínculo Institucional: Instituto de Ciência Política, UnB, Brasília, DF, Brasil.

Carolina Almeida de Paula (carolina.almeidapaula@gmail.com) é Doutora em Ciência Política pelo Instituto de Estudos Sociais e Políticos da Universidade Estadual do Rio de Janeiro (IESP-UERJ) e faz o pós-doutorado na mesma universidade (bolsista FAPERJ). Vínculo Institucional: Instituto de Estudos Sociais e Políticos, UERJ, Rio de Janeiro, RJ, Brasil.

Adriano da Nóbrega Silva (adrianodanobrega@gmail.com) é Doutor em Ciência Política pela Universidade de Brasília (UnB). Vínculo Institucional: Instituto de Ciência Política, UnB, Brasília, DF, Brasil.

\section{Referências}

Almeida, M.H.T., 2005. Recentralizando a federação? Revista de Sociologia \& Política, 24, pp.29-40. DOI: 10.1590/S010444782005000100004

Ames, B., 2001. The Deadlock of Democracy in Brazil. Ann Harbor: The University of Michigan Press. 2012. A estratégia eleitoral na representação proporcional com lista aberta. Cadernos Metrópole, 14(27), pp.59-88. 1995. Electoral Rules, Constituency Pressures, and Pork Barrel: Bases of Voting in the Brazilian Congress. Journal of Politics, 57(2), pp.201-225. DOI: 10.2307/2960309

Ames, B.; Baker, A. \& Rennó, L., 2008. The Quality of Elections in Brazil: Policy, performance, pageantry or pork? In P. Kingstone \& T. Power, eds. Democratic Brazil Revisited. Pittsburgh: University of Pittsburgh Press.

Amorim Neto, O., 2007. O Poder Executivo, centro de gravidade do Sistema Político Brasileiro. In L. Avelar \& A.O. Cintra, eds. O sistema político brasileiro. São Paulo: Editora Unesp/Fundação Konrad-Adenauer.

Arretche, M., 2007. The Veto Power of Sub-National Governments in Brazil: Political institutions and parliamentary behaviour in the post-1988 period. Brazilian Political Science Review, 1(2), pp.40-73. DOI: 10.1590/s1981-38212007000200002

Avelino, G.; Biderman, C. \& Silva, G.P., 2011. A concentração eleitoral nas eleições paulistas: medidas e aplicações. Dados, 54(2), pp.319-347. DOI: 10.1590/s0011-52582011000200004

Borges, A., 2005. Conexão Eleitoral e Atuação Parlamentar - representantes e bases eleitorais no Maranhão. Tese de Doutorado. Rio de Janeiro: IUPERJ.

2013. Eleições presidenciais, federalismo e política social. Revista Brasileira de Ciencias Sociais, 28(81), pp.117-136.

Bourdoukan, A.Y., 2006. Trajetórias de Carreira e Arenas Políticas. In V Encontro da Associação Brasileira de Ciência Política. Belo Horizonte.

Carey, J.M. \& Shugart, M.S., 1995. Incentives to Cultivate a Personal Vote: A rank ordering of electoral formulas. Electoral Studies, 14(4), pp.417-439. DOI: 10.1016/0261-3794(94)00035-2

Carvalho, N.R., 2003. E no Início eram as Bases: geografia política do voto e comportamento legislativo no Brasil. Rio de Janeiro: Revan.

Colomer, J.M. \& Negretto, G.L., 2005. Can Presidentialism Work Like Parliamentarism? Government \& Opposition, 40(1), pp.60-89. DOI: 10.1111/j.1477-7053.2005.00143.x

Cox, G.W. \& Morgenstern, S., 2001. Latin America's Reactive Assemblies and Proactive Presidents. Comparative Politics, 33(2), pp.171-189. DOI: 10.1017/cbo9780511615665.016

Dias, J., 1991. O jogo e os jogadores: legislação eleitoral e padrões de competição política. Rio de Janeiro. Dissertação de Mestrado. Rio de Janeiro: IUPERJ.

Diaz-Cayeros, A.; Magaloni, B. \& Weingast, B., 2003. Tragic Brilliance: Equilibrium Hegemony and Democratization in Mexico. Digit. Disponível em https://www.researchgate.net/publication/241628440_Tragic_Brilliance_Equilibrium_Hegemony_And_Democratization_in_Mexico. Acesso em 2 maio 2016.

Fenwick, T.B., 2009. Avoiding Governors: The Success of Bolsa Família. Latin American Research Review, 44(1), pp.102-131. DOI: 10.1353/lar.0.0073

Fiorina, M.P., 1977. The Case of the Vanishing Marginals: The bureaucracy did it. The American Political Science Review, 71(1), pp.177-181. DOI: $10.2307 / 1956961$

Fleischer, D., 1976. Concentração e dispersão eleitoral: um estudo da distribuição geográfica do voto em Minas Gerais, 1966-1974. Revista Brasileira de Estudos Políticos, 43.

Indjaian, L., 1981. Análise Preliminar da bancada federal paulista eleita pelo MDB em 1978. Relatório parcial de pesquisa apresentado à FAPESP.

Golder, M., 2006. Presidential Coattails and Legislative Fragmentation. American Journal of Political Science, 50(1), pp.34-48. DOI: 10.1111/j.1540-5907.2006.00168.x

Inácio, M., 2011. Engajamento Parlamentar no Brasil. In T. Power \& C. Zucco, eds. O Congresso por ele mesmo: autopercepções da classe política brasileira. Belo Horizonte: Editora UFMG.

Jacobson, G., 2009. The Politics of Congressional Elections. New York: Person/Longman. 
Lemgruber, M., 2010. Participação dos deputados na Comissão Mista de Orçamento e Reeleição. Revista de Políticas Públicas e Gestão Governamental, 9(1), pp.87-104.

Leoni, E.; Pereira, C. \& Rennó, L., 2003. Estratégias para sobreviver politicamente: escolhas de carreiras na Câmara de Deputados do Brasil. Opinião Pública, 9(1), pp. 44-67. DOI: 10.1590/s0104-62762003000100002

Lima, I.A., 2013. Carreira e motivações parlamentares: padrões de trajetória de deputados federais e a alternância entre cargos no Poder Executivo e Legislativo. Monografia. Brasília: Universidade de Brasília.

Mainwaring, S., 1997a. Multipartism, Robust Federalism, and Presidentialism in Brazil. In S. Mainwaring \& M.S. Shugart, eds. Presidentialism and Democracy in Latin America. Cambridge, UK: Cambridge University Press. 1997b. Presidentialism in Brazil: The impact of strong constitutional powers, weak partisan powers, and robust federalism. In S. Mainwaring \& M.S. Shugart, eds. Presidentialism and Democracy in Latin America. Cambridge, UK: Cambridge University Press.

Marenco, A. \& Serna, M., 2007. Por que carreiras políticas na esquerda e na direita não são iguais? Recrutamento legislativo em Brasil, Chile e Uruguai. Revista Brasileira de Ciencias Sociais, 22(64), pp.93-113. DOI: 10.1590/s010269092007000200008

Mayhew, D.R., 2005. Congress: The electoral connection. $2^{\text {nd }}$ ed. New Haven: Yale University Press.

Mesquita, L., 2008. Emendas ao orçamento e conexão eleitoral na Câmara dos Deputados Brasileira. Dissertação de Mestrado. São Paulo: Universidade de São Paulo.

Nicolau, J., 2007. O Sistema Eleitoral de Lista Aberta no Brasil. In J. Nicolau \& T. Power, eds. Instituições representativas no Brasil: balanço e reforma. Belo Horizonte: Editora UFMG.

Paranhos, R.et al., 2014. Onde os fracos não têm vez. Reeleição parlamentar no Brasil (1994-2010). In $9^{\circ}$ Encontro da ABCP. Brasília.

Pereira, C. \& Rennó, L., 2001. O que É que o Reeleito Tem? Dinâmicas Político-Institucionais Locais e Nacionais nas Eleições de 1998 para a Câmara dos Deputados. Dados, 44(2), pp.133-172. DOI: 10.1590/s0011-52582001000200004

,2007. O que é que o reeleito tem? O retorno: o esboço de uma teoria da reeleição no Brasil. Revista de Economia Política, 27(4), pp.664-683. DOI: 10.1590/S0101-31572007000400010

Raile, E.D.; Pereira, C. \& Power, T., 2011. The Executive Toolbox: Building legislative support in a multiparty presidential regime. Political Research Quarterly, 64(2), pp.323-334. DOI: 10.1177/1065912909355711

Samuels, F., 2003. Ambition, Federalism, and Legislative Politics in Brazil. Cambridge, UK: Cambridge University Press.

Santana, L., 2008. Perfil, trajetórias e ambição política dos legisladores na construção de suas carreiras: Argentina, Brasil, Chile e Uruguai. Teoria \& Sociedade, 16(2), pp.130-155.

Santos, F., 2003. O Poder Legislativo no Presidencialismo de Coalizão. Rio de Janeiro: IUPERJ.

Shefter, M., 1994. Political Parties and the State the American Historical Experience. Princeton: Princeton University Press.

Shugart, M. \& Carey, J.M., 1992. Presidents and Assemblies: Constitutional design and electoral dynamics. Cambridge, UK: Cambridge University Press.

Silva, et al., 2010. Competição Política e Sistema Eleitoral Brasileiro: algumas evidências empíricas. In $8^{\circ}$ Encontro da ABCP. Recife.

Soares, G., 2001. A democracia interrompida. Rio de Janeiro: Editora da Fundação Getúlio Vargas.

Soares, M.M., 2013. Influência Majoritária em eleições proporcionais: os efeitos presidenciais e governatoriais sobre as eleições para a Câmara dos Deputados Brasileira (1994-2010). Dados, 56(2), pp.413-437. DOI: 10.1590/s001152582013000200006

Stokes, S.C., 2005. Perverse Accountability: A formal model of machine politics with evidence from Argentina. The American Political Scicence Review, 99(3), pp.315-325. DOI: 10.1017/s0003055405051683

Terron, S.L. 2012. Geografia Eleitoral em Foco. Em Debate, 4, pp.8-18.

Veiga, L. et al., 2008. Conexão Eleitoral em uma Assembléia Legislativa: a atuação do parlamentar e atitude do eleitor. In $6^{\circ}$ Encontro da ABCP. Campinas.

Wood, D.B. \& Waterman, R.B., 1991. The Dynamics of Political Control of the Bureaucracy. The American Political Science Review, 85(3), pp.801-828. DOI: 10.2307/1963851 


\section{Abstract}

The article analyzes the impact of governing coalitions at the national and state levels on the geography of the vote in Brazilian elections to the federal chamber. Our central claim is that the government-opposition divide has a very strong impact on the territorial distribution of parties' and candidates' vote. Candidates affiliated with parties that integrate governing coalitions at the national and state levels simultaneously have a much greater likelihood of obtaining geographically dispersed and dominant vote distributions within the state's territory. We argue, further, that this effect weakens incumbency advantage in legislative elections. The empirical analysis relies on a large dataset with information on indexes of domination and concentration of the vote for all candidates to the Federal Chamber from 1998 to 2010. Statistical results confirm that candidates affiliated with parties that are members of governing coalitions at the federal and state level display much more often fragmented-dominant voting patterns. Also, the empirical evidence indicates that the effect of incumbency on electoral domination is less relevant than the benefits of access to resources controlled by the federal executive. The article concludes that traditional hypotheses on the electoral connection deserve to be reassessed considering the preponderance of Executives and strong subnational governments in Brazil's presidentialism.

KEYWORDS: electoral geography; legislative elections; federalism; presidentialism; electoral connection.

This is an Open Access article distributed under the terms of the Creative Commons Attribution Non-Commercial License which permits unrestricted non-commercial use, distribution, and reproduction in any medium provided the original work is properly cited. 